\title{
Neural systems implicated in delayed and probabilistic reinforcement
}

\author{
Rudolf N. Cardinal* \\ Department of Experimental Psychology, University of Cambridge, Downing Street, Cambridge CB2 3EB, United Kingdom \\ Cambridge University Hospitals NHS Foundation Trust, Addenbrooke's Hospital, Hills Road, Cambridge CB2 2QQ, United Kingdom
}

Received 14 November 2005; accepted 30 March 2006

\begin{abstract}
This review considers the theoretical problems facing agents that must learn and choose on the basis of reward or reinforcement that is uncertain or delayed, in implicit or procedural (stimulus-response) representational systems and in explicit or declarative (action-outcome-value) representational systems. Individual differences in sensitivity to delays and uncertainty may contribute to impulsivity and risk taking. Learning and choice with delayed and uncertain reinforcement are related but in some cases dissociable processes. The contributions to delay and uncertainty discounting of neuromodulators including serotonin, dopamine, and noradrenaline, and of specific neural structures including the nucleus accumbens core, nucleus accumbens shell, orbitofrontal cortex, basolateral amygdala, anterior cingulate cortex, medial prefrontal (prelimbic/infralimbic) cortex, insula, subthalamic nucleus, and hippocampus are examined.
\end{abstract}

(C) 2006 Elsevier Ltd. All rights reserved.

Keywords: Delay; Uncertainty; Risk; Impulsivity; Instrumental conditioning; Rat

\section{Delayed and uncertain reinforcement: The problems of learning and choice}

Natural and artificial learning agents must grapple with the problem of selecting actions to achieve the best possible outcome under their value system. However, the outcome of a given action is not always certain and immediate. Outcomes are frequently uncertain: agents do not always obtain that for which they work. Furthermore, when an agent acts to obtain reward or reinforcement, there is often a delay between its action and the ultimate outcome. This applies both to positive reinforcers (things whose presentation increases the likelihood of preceding actions) and negative reinforcers (things whose removal increases the likelihood of preceding actions) (Skinner, 1938), though this article will focus on positive, or appetitive, reinforcers, such as food; the term 'reward' will also be used for an appetitive positive reinforcer. For optimal performance, therefore, agents must learn and choose on the basis of reward or reinforcement that is uncertain or delayed.

\footnotetext{
* Corresponding address: Department of Experimental Psychology, University of Cambridge, Downing Street, Cambridge CB2 3EB, United Kingdom. Tel.: +44 7092 340641; fax: +44 7092340645 .

E-mail address: Rudolf.Cardinal@pobox.com.
}

Agents may act procedurally, meaning that they act without a representation of the outcome of their actions, merely on the basis that an action has been reinforced or led to unspecified 'good things' before. Direct links between representations of triggering stimuli and particular responses exemplify procedural responding, or stimulus-response (S-R) learning; the $\mathrm{S}-\mathrm{R}$ links are strengthened in some way as a result of the arrival of reinforcement, but without the nature of that reinforcement being explicitly encoded. Alternatively, or additionally, agents may encode the outcomes of their actions explicitly, and use these explicit (sometimes termed declarative) representations of anticipated actions when choosing what to do. Animals exhibit both stimulus-response (procedural) and truly goal-directed or action-outcome (declarative) responding (Cardinal, Parkinson, Hall, \& Everitt, 2002; Dickinson, 1994; Dickinson \& Balleine, 1994). This complicates the analysis of motivated behaviour in animals, including the analysis of learning with and choosing uncertain and delayed rewards.

In an S-R learning system, it is easy to envisage connectionist mechanisms by which uncertain and delayed reinforcers could drive learning. Suppose an agent experiences its world, causing many different 'stimulus units' to become activated, and suppose it acts randomly by activating different 'response units'. Let us consider the basic case of appetitive, certain, immediate reinforcement. Suppose a hard-wired 
mechanism exists to detect events of innate importance to the agent (such as food to a hungry animal). Suppose also that this mechanism, upon detecting an important appetitive event, triggers an internal reinforcement signal that acts to strengthen links between currently active units (stimulus units and response units). By strengthening links between units representing the stimuli currently being perceived and the response currently executing, this simple system would reinforce the response, i.e. increase the probability of executing the response again in the same situation. These S-R links do not encode the nature of the food. If the relationship between responses and food is uncertain, i.e. if $0<P$ (outcome | action $)<1$, then the $\mathrm{S}-\mathrm{R}$ connections will be strengthened on occasions when food is delivered, but not strengthened on occasions when it is not. S-R links would thus develop to reflect the statistical relationships between actions and reward in a particular stimulus environment: more reliable action-outcome contingencies in the environment come to be reflected in stronger S-R links. To extend this to delayed reinforcement, when the time $t$ (action $\rightarrow$ outcome) $>0$, requires that some representation of recently executed responses remains active until the reinforcing outcome actually arrives, if the correct response is to be reinforced. If the action representation decays gradually (or if it persists until a new action is begun, and the probability of remaining in the same 'action state' therefore declines with time), then the likelihood of reinforcing the correct response will decline gradually as action-outcome delays increase, and the agent will learn less well as reinforcement is progressively delayed. None of these ideas are new (Grindley, 1932; Guthrie, 1935; Hull, 1932, 1943; Killeen \& Fetterman, 1988; Mackintosh, 1974; Mowrer, 1960; Revusky \& Garcia, 1970; Spence, 1956; Thorndike, 1911).

In a goal-directed (action-outcome) learning system, the agent must encode both the action-outcome relationship and the value of the outcome, and these two representations must interact to determine the probability of selecting a given action (Cardinal, Parkinson, Hall, et al., 2002; Dickinson, 1980, 1994; Dickinson \& Balleine, 1994; Tolman, 1932). Declarative representations are substantially harder to represent using a simple connectionist framework (Holyoak \& Spellman, 1993; Shastri \& Ajjanagadde, 1993; Sougné, 1998). The problem of detecting and encoding the action-outcome relationship (the consequences of the agent's actions) is itself complex, but the additional issues concerning uncertain and delayed outcomes are much the same as in the S-R case. That is to say, it may be more difficult to learn that an action causes a given outcome if that outcome is inconsistent or delayed. On top of this, even if the agent knows perfectly well that an action produces an outcome with a certain probability and/or a certain delay, the agent may value uncertain or delayed rewards less than certain or immediate rewards, reducing the likelihood of its choosing that action. For example, if we ask a man whether he prefers $£ 10$ now or $£ 20$ next week, we usually assume that he represents the action-outcome contingencies equally (i.e. that he believes that selecting the ' $£ 10$ now' option is as likely to produce $£ 10$ now as selecting the ' $£ 20$ next week' option is to produce $£ 20$ next week) and that his choice simply reflects the relative value to him of the two options. On the other hand, if we train rats to press levers for (say) immediate and delayed reward, we must bear in mind the possibility of inequalities both in the representation of the action-outcome contingency for immediate and delayed reward, and in the values of the two outcomes-not to mention differences in S-R learning that the delays may engender. There are few mechanistic models of explicit (declarative) delay or uncertainty coding applicable to animal learning, although a recent model proposes the encoding of action uncertainty as a way of mediating competition between goal-directed and S-R responding (Daw, Niv, \& Dayan, 2005a, 2005b).

\section{Individual differences: Risk taking and impulsivity}

Individual differences in responsivity to uncertain or delayed reinforcement are also of considerable interest. When making decisions under conditions of uncertainty, individuals vary as to how much uncertainty or risk they are willing to tolerate. Formally, individuals differ in how much they discount the value of reinforcers as the uncertainty of the reinforcer increases (i.e. as the probability of the reinforcer declines, or the odds against obtaining the reinforcer increase) (Ho, Mobini, Chiang, Bradshaw, \& Szabadi, 1999). Risk taking is one aspect of the personality trait of impulsivity (Daruna \& Barnes, 1993; Evenden, 1999a; Eysenck, 1993) and is a feature of a number of psychiatric disorders, including pathological gambling and certain personality disorders (APA, 2000; Coccaro \& Siever, 1995; Holt, Green, \& Myerson, 2003; Roy, DeJong, \& Linnoila, 1989). The term 'risk' implies exposure to the possibility of an aversive consequence (OUP, 1997), which may include the possibility of not obtaining an anticipated reward. In the appetitive domain, risk taking is exemplified by the tendency to choose large rewards that are very uncertain, in preference to smaller, certain rewards. Abnormal risk taking may reflect dysfunction of reinforcement learning systems that mediate the effects of uncertain reward or punishment.

Furthermore, individual variation in the ability to use delayed reinforcement may determine another aspect of impulsivity: an animal able to forgo short-term poor rewards in order to obtain delayed but better rewards may be termed self-controlled, whereas an animal that cannot tolerate delays to reward may be said to exhibit impulsive choice (Ainslie, 1975, 2001; Evenden, 1999a, 1999b). Abnormalities in learning from delayed reinforcement may be of considerable clinical significance (Rahman, Sahakian, Cardinal, Rogers, \& Robbins, 2001). Impulsivity is part of the syndrome of many psychiatric disorders, including mania, drug addiction, antisocial personality disorder, and attentiondeficit/hyperactivity disorder (APA, 2000). Impulsivity is a broad concept that may be divided into preparation impulsivity (failure to take all relevant information into account before making a decision), execution or 'motor' impulsivity (termination of a behavioural chain before the goal is reached), and outcome or 'choice' impulsivity (choice of a quick but less valuable outcome rather than a later but more valuable outcome). These measures may be pharmacologically 
dissociated (Evenden, 1999a, 1999b). Impulsive choice, one aspect of impulsivity, may reflect dysfunction of reinforcement learning systems mediating the effects of delayed rewards (Ainslie, 1975; Sagvolden \& Sergeant, 1998).

\section{Learning with delayed reinforcement in normal animals}

Delays can hamper both Pavlovian and instrumental conditioning (Dickinson, 1980, 1994; Gallistel, 1994; Hall, 1994; Mackintosh, 1983): for example, instrumental conditioning has long been observed to be systematically impaired as the outcome is delayed (Dickinson, Watt, \& Griffiths, 1992; Grice, 1948; Harker, 1956; Lattal \& Gleeson, 1990; Perin, 1943; Skinner, 1938). Despite this, normal rats have been shown to acquire free-operant responding with programmed response-reinforcer delays of up to $32 \mathrm{~s}$, or even $64 \mathrm{~s}$ if the subjects are pre-exposed to the learning environment (Dickinson et al., 1992). Delays do reduce the asymptotic level of responding (Dickinson et al., 1992), though the reason for this is not clear. There are several psychological reasons why action-outcome delays might impair learning or performance of an instrumental response (Ainslie, 1975; Cardinal, Winstanley, Robbins, \& Everitt, 2004). As discussed above, it may be that when subjects learn a response with a substantial response-reinforcer delay, they never succeed in representing the instrumental action-outcome contingency fully. Alternatively, they may value the delayed reinforcer less. Finally, the delay may also retard the acquisition of a procedural stimulus-response habit and this might account for the decrease in asymptotic responding. It is presently not known whether responses acquired with delayed reinforcement are governed by a different balance of habits and goal-directed actions than responses acquired with immediate reinforcement.

Two additional factors must be considered. Cues or signals present during the delay to the reinforcer may become associated with the primary reinforcer, becoming conditioned reinforcers capable of reinforcing actions themselves; conditioned reinforcers may therefore help to bridge action-outcome delays. Indeed, such signals tend to increase responding for delayed reinforcers (Lattal, 1987; Mazur, 1997). One other important factor in learning to act using delayed reinforcement may be the role of the environmental context. The animal's task is to attribute the outcome to its actions; instead, it may erroneously associate the outcome with the context, since the context is a cue that is temporally closer to the outcome than the action is. The longer the delay, the more this contextual competition comes to impair the learning of the action-outcome contingency. Instrumental conditioning with delayed reinforcement can be enhanced if rats are exposed to the relevant contextual cues prior to instrumental training, and this enhancement is lessened if 'free' (non-contingent) rewards are given during the contextual pre-exposure periods (Dickinson \& Balleine, 1994; Dickinson et al., 1992). These results are consistent with the theory that during the action-outcome delay, contextual cues compete with the action to become associated with the outcome; pre-exposing the animals to the context with no consequences reduces this contextual competition, by making the context a bad predictor of the outcome (perhaps via latent inhibition or learned irrelevance), and this in turn makes the action-outcome contingency more salient and easier to learn (Dickinson \& Balleine, 1994; Dickinson et al., 1992).

\section{Choice with delayed and uncertain reinforcement in normal animals}

\subsection{Delayed and probabilistic reinforcement: Equivalent or distinct processes?}

It has been suggested that delay (or temporal) discounting, the process by which delayed reinforcers lose value, and probability (or odds) discounting, the process by which uncertain reinforcers lose value, reflect the same underlying process (Green \& Myerson, 1996; Mischel, 1966; Mazur, 1989, 1995, 1997; Rachlin, Castrogiovanni, \& Cross, 1987; Rachlin, Logue, Gibbon, \& Frankel, 1986; Rachlin, Raineri, \& Cross, 1991; Rotter, 1954; Sozou, 1998; Stevenson, 1986). For example, choosing an uncertain reinforcer five times but only obtaining it on the fifth response might be seen as equivalent to a very long delay, on average, between choice of the reinforcer and its eventual delivery. Alternatively, delays may be seen as entailing the ecological risk of losing the reward during the delay. In animal models, while subjects are learning to respond for delayed or probabilistic rewards, both may initially be similarly unpredictable (although delayed rewards can become more accurately predicted following learning in a manner that stochastic rewards cannot). However, there is evidence that time and probability discounting are different and dissociable processes (Green \& Myerson, 2004; Ho et al., 1999; Mitchell, 2003). Most simply, it is not surprising that currency inflation affects human decisions involving delayed but not probabilistic financial reward (Ostaszewski, Green, \& Myerson, 1998). Moreover, the absolute magnitude of rewards can have different effects on delayed and probabilistic discounting (Green \& Myerson, 2004; Green, Myerson, \& Ostaszewski, 1999; Myerson, Green, Hanson, Hold, \& Estle, 2003). A study looking at human choices in a gambling task found that individuals' propensity to choose rapidly (one, perhaps motoric, measure of delay aversion) and their propensity to bet large amounts of money on uncertain outcomes (a measure of risk taking) represented independent factors (Deakin, Aitken, Robbins, \& Sahakian, 2004). Some studies have found abnormal delay discounting, but not uncertainty discounting, in drug addicts (Mitchell, 1999, 2003; Reynolds, Richards, Horn, \& Karraker, 2004; Vuchinich \& Calamas, 1997), while gamblers have been observed to discount probabilistic rewards less steeply than controls (i.e. to take risks) without showing differences in delay discounting (Holt et al., 2003).

\subsection{Delay discounting}

In a typical delayed reinforcement choice task, a subject chooses between an immediate, small ('smaller, sooner' or SS) reward or a large, delayed ('larger, later' or LL) reward; the 

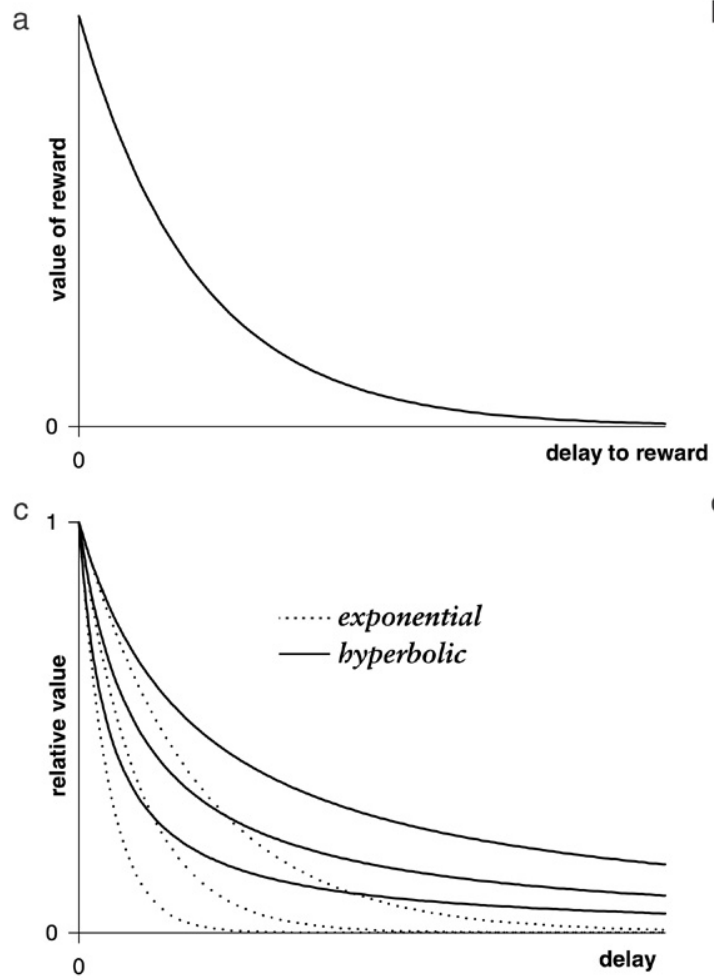

b
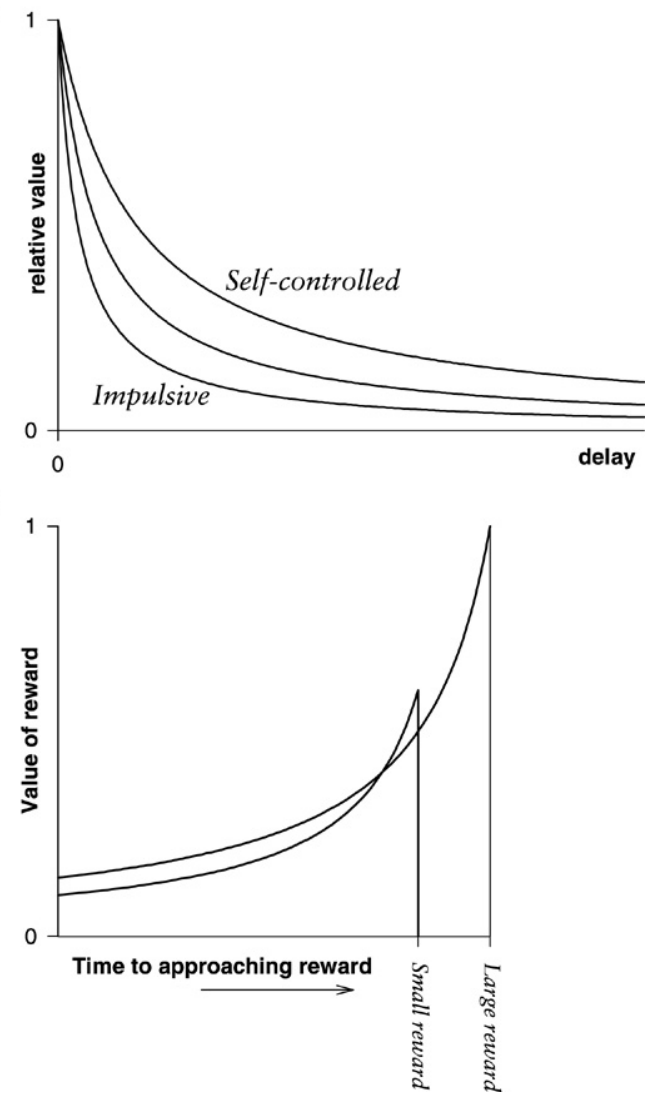

Fig. 1. Temporal discounting. (a) The basic, intuitive, and well-validated phenomenon of temporal discounting is that the subjective value of a reward declines monotonically as the reward is progressively delayed: all other things being equal, immediate rewards are worth more than delayed rewards. (b) Individuals may vary in their propensity to discount delayed rewards. Individuals who discount the future steeply are said to be impulsive; individuals who discount the future shallowly (giving the future greater relative weight) are said to be self-controlled. (c) Different mathematical models of temporal discounting have been proposed; exponential and hyperbolic discounting are shown. Exponential temporal discounting is described by the equation value $=$ immediate value $\times \mathrm{e}^{-K \cdot d e l a y}$. Hyperbolic temporal discounting is governed by the equation value $=$ immediate value $/(1+K \cdot$ delay). Large values of the discounting parameter $K$ give the steepest curve (the most impulsive behaviour) in both cases. There is strong empirical support for the hyperbolic, not the exponential, discounting model; one critical difference in the predictions of these two models is the phenomenon of preference reversal, since hyperbolic discounting allows curves for different rewards to cross. (d) Preference reversal, illustrated for two hypothetical rewards. Given a choice between an early reward of value 0.6 and a later reward of value 1 , hyperbolic discounting predicts that the larger reward will be chosen if the choice is made far in advance (towards the left of the graph). However, as time advances, there may come a time just before delivery of the small reward when the value of the small reward exceeds that of the large reward; preference reverses and the small reward is chosen. Figures adapted from Ainslie (1975) (and also published in Robbins et al. (2005)).

temporal discounting function quantifies the effect of the delay on preference (Fig. 1). Early models of choice assumed an exponential model of temporal discounting (see Kacelnik (1997a)), so that if $V_{0}$ is the value of a reinforcer delivered immediately, then the value of a reinforcer delivered after time $t$ is

$V_{t}=V_{0} \mathrm{e}^{-K t}$

where $K$ quantifies an individual's tendency to 'discount' the future (to value delayed rewards less). The exponential model makes intuitive sense, whether you consider the underlying process to be one in which the subject has a constant probability of 'forgetting' its original response per unit time (making it progressively less available for reinforcement), one in which the 'strength' of the response's representation decays to a certain proportion of its previous value at each time step, or one in which the subject behaves as if there is a constant probability of losing the delayed reward per unit of waiting time. A S-R learning view accounts for some of the theoretical appeal of exponential temporal discounting models: in exponential decay, at any one moment in time the trace strength of a response follows directly from the trace strength at the previous instant (if $x_{t}$ is the trace strength at time $t$ and $A$ is the starting value, then $x_{t}=$ $x_{0} \mathrm{e}^{-k t}$ and $x_{t+1}=\mathrm{e}^{-k} x_{t}$ ). However, the exponential model has been emphatically rejected by experimental work with humans and other animals. Instead, temporal discounting appears to follow a hyperbolic or very similar discount function, such as

$V=\frac{V_{0}}{1+K t}$

(Grace, 1996; Grice, 1948; Mazur, 1987; Mazur, Stellar, \& Waraczynski, 1987; Richards, Mitchell, de Wit, \& Seiden, 1997). One interesting prediction that emerges from hyperbolic (but not exponential) models is that preference between a large and a small reward should be observed to reverse depending on the time that the choice is made (Fig. 1), and such preference reversal is a reliable and important experimental finding (see Ainslie (1975, 2001), Bradshaw and Szabadi (1992) and Green, Fisher, Perlow, and Sherman (1981)). In the hyperbolic 
discounting model and all others in which preference reversal occurs, the value at any one moment cannot be calculated directly from the value immediately preceding it in time; therefore, hyperbolic discounting suggests that more information is being maintained by the agent.

It is not known why hyperbolic discounting arises (Kacelnik, 1997a), or what neuropsychological processes are responsible for it. Such discounting might in principle result from some combination of poor knowledge of the contingencies between actions and their outcomes at long delays, or from weak S-R habits, or because subjects are perfectly aware that the delayed reward is available but assign a low value to it (Cardinal, Robbins, \& Everitt, 2003). Hyperbolic discounting might also be explicable as the overall effect of two or more different systems-for example, a cognitive, declarative system that exhibits minimal or exponential discounting, plus phenomena such as Pavlovian-instrumental transfer (PIT), conditioned salience, or 'visceral factors' that make rewards more salient and promote their choice when they are immediately available (Cardinal, Robbins, et al., 2003; Gjelsvik, 2003; Loewenstein, 1996; Loewenstein \& O’Donoghue, 2004). As discussed above, perhaps the most obvious difference between studies of human impulsive choice and animal models is that humans can be offered explicit choices (hypothetical or real: the difference does not appear to be important; Lagorio and Madden (2005)) without prior experience of the situation (de Wit, Enggasser, \& Richards, 2002; Myerson \& Green, 1995; Rachlin et al., 1991)_- 'pre-packaged' action-outcome contingencies. Other animals must learn these contingencies through experience, implying that the whole gamut of psychological representations that contribute to their actions (including goal-directed actions, $\mathrm{S}-\mathrm{R}$ habits, and conditioned reinforcers) can influence their choices.

\subsection{Uncertainty discounting}

Similarly, the dominant model of uncertainty or probability discounting (Green \& Myerson, 2004; Ho et al., 1999; Rachlin et al., 1986, 1991) suggests that subjects calculate a value for each reinforcer, according to its size and other parameters, and discount this by multiplying it by $1 /(1+H \theta)$, where $\theta$ represents the odds against obtaining the reinforcer, $\theta=$ $(1-p) / p$ where $p$ is the probability of obtaining the reinforcer, and $H$ represents an odds discounting parameter that is specific to the individual subject but stable over time for that subject. In this model, value is a hyperbolic function of the odds $\theta$ :

$V=\frac{\text { magnitude }}{1+H \cdot \theta}$.

Such a hyperbolic function is supported by empirical research, at least in humans (Kacelnik, 1997b; Rachlin, Brown, \& Cross, 2000; Rachlin et al., 1986, 1991; Rachlin \& Siegel, 1994; Richards, Zhang, Mitchell, \& de Wit, 1999). Ho et al. (1999) further suggest that hyperbolic processes of discounting apply to the delay, probability (odds), and magnitude of a reward, and that these three discounting processes are independent, multiplicative, and each governed by its own discounting parameter ( $K$ for delay, $H$ for probability/odds, $Q$ for magnitude) that is relatively stable for an individual. Their combined model is therefore as follows:

$$
V=\frac{1}{1+K \cdot \text { delay }} \times \frac{1}{1+H \cdot \theta} \times \frac{\text { magnitude }}{\text { magnitude }+Q} .
$$

It should be noted in passing that although effects of delay, probability, magnitude, and so forth are often assumed to be calculated independently (Ho et al., 1999; Killeen, 1972; Rachlin et al., 1991), and though there is some support for this assumption (Mazur, 1987, 1997), others have found that the effects of reinforcer delay and magnitude are not independent (Ito, 1985; White \& Pipe, 1987). In addition, as discussed below in the context of drug addiction, humans may show quantitatively different temporal (delay) discounting for qualitatively different reinforcers, such as drugs and money. Furthermore, deprivation of one commodity can selectively increase preference for SS over LL rewards for that commodity (e.g. Mitchell (2004a)), suggesting that parameters such as $K$ and/or $Q$ are not unitary parameters that apply to all reinforcers, and/or that additional parameters specific to reinforcer classes must be added to characterize behaviour fully.

\section{Systemic pharmacological studies}

Given the importance of impulsive choice in disorders such as addiction (Bickel, Odum, \& Madden, 1999; Evenden, 1999a; Heyman, 1996; Mitchell, 1999; Poulos, Le, \& Parker, 1995) and attention-deficit/hyperactivity disorder (ADHD) (Sagvolden, Aase, Zeiner, \& Berger, 1998; Sagvolden \& Sergeant, 1998), a number of groups have studied the effects on impulsive choice of manipulating neurochemical and neuroanatomical systems implicated in these disorders. I will review pharmacological and neurochemical studies first. To date, more have examined choice involving delayed reinforcement than choice involving uncertain reinforcement, and many more have used appetitive positive reinforcement (reward) than aversive reinforcement (such as punishment).

\subsection{Serotonin $(5-H T)$}

Serotonin (5-hydroxytryptamine, 5-HT) has long been implicated in impulse control. Drugs that suppress 5-HT function were observed to reduce behavioural inhibition, making animals more impulsive in a 'motor' sense, as defined above (Evenden, 1999b; Soubrié, 1986). Correlational studies have indicated that low cerebrospinal fluid (CSF) levels of the 5-HT metabolite 5-hydroxyindoleacetic acid (5-HIAA) are associated with risk taking in monkeys (Evenden, 1998; Mehlman et al., 1994) and impulsive aggression, violence, and suicide in humans (Åsberg, Träskman, \& Thorén, 1976; Brown \& Linnoila, 1990; Linnoila, Virkkunen, George, \& Higley, 1993; Linnoila et al., 1983; Mann, 2003).

Forebrain 5-HT depletion leads to impulsive choice in a variety of paradigms (Bizot, Le Bihan, Puech, Hamon, \& Thiébot, 1999; Mobini, Chiang, Ho, Bradshaw, \& Szabadi, 2000; Richards \& Seiden, 1995; Wogar, Bradshaw, \& Szabadi, 1993) and has been suggested to steepen the temporal 
discounting function, such that delayed rewards lose their capacity to motivate or reinforce behaviour (Ho et al., 1999; Mobini, Chiang, Al-Ruwaitea, et al., 2000; Wogar et al., 1993). The 5-HT-depleted animal becomes hypersensitive to delays (or hyposensitive to delayed reward). As delayed rewards have unusually low value, the animal chooses SS rewards over LL rewards, a characteristic of impulsivity (Ainslie, 1975). Conversely, increasing 5-HT function with the 5-HT indirect agonist fenfluramine decreases impulsive choice (Poulos, Parker, \& Le, 1996). Since choice between SS and LL rewards may be affected by changes in sensitivity to reinforcer magnitude as well as reinforcer delay (Ho et al., 1999), it is important to note that 5-HT depletion does not appear to alter reinforcer magnitude discrimination (Mobini, Chiang, AlRuwaitea, et al., 2000; Mobini, Chiang, Ho, et al., 2000).

Altered 5-HT function has also been strongly implicated in depression (see e.g. Caspi et al. (2003), Delgado et al. (1990) and Feldman, Meyer, and Quenzer (1997, pp. 842-847)), but the relationship between depression, impulsivity, and 5HT is complex. The precise neurochemical abnormality or set of abnormalities in depression is far from clear (e.g. Dhaenen (2001), Feldman et al. (1997) and Stockmeier (2003)). There is no clear-cut relationship between depression itself and levels of 5-HIAA in the CSF (Åsberg, 1997; Feldman et al., 1997, p. 843), although antidepressant drugs themselves tend to lower CSF 5-HIAA (see Bäckman, Alling, Alsén, Regnéll, and Träskman-Bendz (2000)). However, there is a consistent association between low CSF 5-HIAA and suicidal behaviour-not only in depression, but also in schizophrenia and other disorders (see Åsberg (1997), Cooper, Kelly, and King (1992), Cremniter et al. (1999), Träskman-Bendz, Åsberg, and Schalling (1986)). Patients who are prone to suicide, many of whom are depressed, show high impulsivity (Apter, Plutchik, \& van Praag, 1993; Corruble, Benyamina, Bayle, Falissard, \& Hardy, 2003; Plutchik \& Van Praag, 1989). Thus, low 5-HT function has been linked with impulsive behaviour, which is a risk factor for suicide, and abnormalities of the 5-HT system are also associated with depression, also a strong risk factor for suicide.

However, the results relating 5-HT to impulsivity are not wholly clear-cut. The effects of forebrain 5-HT depletion to promote impulsive choice have sometimes been transient (Bizot et al., 1999) or not observed (Winstanley, Dalley, Theobald, \& Robbins, 2003), and a nonselective 5-HT antagonist has been observed to promote self-controlled choice (Evenden \& Ryan, 1996). In humans, lowering 5-HT levels via dietary tryptophan depletion (Biggio, Fadda, Fanni, Tagliamonte, \& Gessa, 1974; Clemens, Bennett, \& Fuller, 1980; Delgado, Charney, Price, Landis, \& Heninger, 1989) decreases levels of 5-HT metabolites in cerebrospinal fluid (Carpenter et al., 1998; Williams, Shoaf, Hommer, Rawlings, \& Linnoila, 1999), an indirect indicator of brain 5-HT levels. However, although tryptophan depletion may increase 'motor' impulsivity in some tasks (Walderhaug et al., 2002), it does not affect stop-signal reaction time (Clark et al., 2005; Cools et al., 2005), a basic measure of motor control, and it has not been shown to increase impulsive choice in humans (Crean, Richards, \& de Wit, 2002). Likewise, a recent rodent study found that forebrain 5-HT depletion increased motor impulsivity but not delay discounting (Winstanley, Dalley, Theobald, \& Robbins, 2004). Furthermore, 5-HT efflux in prefrontal cortex (PFC), as measured by in vivo microdialysis (as opposed to CSF metabolite levels or post mortem whole-tissue measurement) centred on the prelimbic cortex (PrL), was unexpectedly found to be positively correlated with premature responding in an attentional task, a form of motor impulsivity (Dalley, Theobald, Eagle, Passetti, \& Robbins, 2002). Post mortem analysis of the same subjects failed to show differences in total tissue 5-HT or 5-HIAA levels between the more impulsive and more self-controlled subgroups. 5-HT may modulate impulsivity in different ways depending on the involvement of different receptor subtypes (Evenden, 1999b; Evenden \& Ryan, 1999; Winstanley, Theobald, Dalley, Glennon, \& Robbins, 2004). Furthermore, the acute effects of serotonergic drugs on impulsivity can be the opposite of the chronic effects (Liu, Wilkinson, \& Robbins, 2004), with evidence for complex adaptations within the PFC 5-HT system.

Although manipulations of 5-HT have influenced choice involving delayed reinforcement, there is less evidence that they influence choice involving uncertainty and risk. Although forebrain 5-HT depletion has affected temporal (delay) discounting, as discussed above, it does not appear to influence choice involving probabilistic reinforcement. Dietary tryptophan depletion has not been shown to affect probability discounting in humans (Anderson, Richell, \& Bradshaw, 2003; Rogers et al., 2003); but see Cools et al. (2005); similarly, forebrain 5-HT depletion in rats does not affect choice between small, certain rewards and large, uncertain rewards (Mobini, Chiang, Ho, et al., 2000).

\subsection{Noradrenaline (NA)}

Relatively little is known about the role of noradrenaline (NA) in delayed or probabilistic reinforcement. It has been suggested that NA neurons encode some aspects of uncertainty in the general sense of making predictions in a given context, in a manner complementary to that of acetylcholine (ACh) ( $\mathrm{Yu}$ \& Dayan, 2005). In causal studies, systemic NA blockade has been shown to affect decision making under uncertainty in humans, by reducing the discrimination between magnitudes of different losses when the probability of losing was high (Rogers, Lancaster, Wakeley, \& Bhagwagar, 2004), though NA re-uptake inhibition has not been shown to affect the Iowa gambling task (O'Carroll \& Papps, 2003), in which subjects must choose between decks of cards differing in magnitude and probability of their expected gains and losses (Bechara, Damasio, Damasio, \& Anderson, 1994).

\subsection{Dopamine (DA)}

\subsubsection{Temporal difference learning and dopamine}

Since prediction of the future is of key importance in designing artificial intelligence agents, a number of mathematical and computational models have been developed 
to learn from delayed and/or probabilistic reinforcement (Russell \& Norvig, 1995), including some forms of Qlearning (Watkins, 1989) and temporal difference (TD) learning (Sutton, 1988). Some models have been compared directly to mammalian neural systems. For example, the TD learning model of Sutton (1988) has been extended to an actor-critic architecture (see Barto (1995) and Houk, Adams, and Barto (1995)). In this scheme, a 'critic' has access to sensory and motor information and primary reinforcement, and learns to predict reward on the basis of this information using a TD algorithm. 'Immediate' reinforcement is held to follow the causing action by one time unit, and the reinforcement at time $t$ is referred to as $r_{t}$. Delayed reinforcement is given a lesser weighting by being multiplied by a factor $\gamma$ for every time step it is delayed (where $0 \leq \gamma<1$ ); high $\gamma$ indicates a strategic or long-term orientation and low $\gamma$ indicates a tactical, shortterm, or impulsive orientation. If the critic is perfect, then its prediction $P$ would be

$P_{t}=r_{t+1}+\gamma r_{t+2}+\gamma^{2} r_{t+3}+\cdots$.

Therefore, the prediction for time $t-1$ would be

$P_{t-1}=r_{t}+\gamma r_{t+1}+\gamma^{2} r_{t+2}+\cdots$

and thus, for perfect prediction,

$P_{t-1}=r_{t}+\gamma\left(r_{t+1}+\gamma r_{t+2}+\cdots\right)$

$P_{t-1}=r_{t}+\gamma P_{t}$

$r_{t}+\gamma P_{t}-P_{t-1}=0$.

The TD error $\delta$ can therefore be defined as

$\delta=r_{t}+\gamma P_{t}-P_{t-1}$.

This quantity $\delta$ represents the difference between predicted and actual reward. The critic learns by adjusting its reinforcement prediction on the basis of the TD error: if $\delta>0$, reward occurred that was not predicted, and the prediction at $t-1$ should be increased for next time; if $\delta<0$, reward was predicted but did not occur, and the prediction at $t-1$ should be decreased. The critic teaches not only itself but also an 'actor', which selects an action, and then modifies the propensity to perform that action on the basis of the TD error (if $\delta=0$, the consequences of the last action were expected; if $\delta>0$, the consequences were better than expected, and the response tendency of the action made at $t-1$ should be strengthened; if $\delta<0$, the consequences were worse than expected, and the response tendency at $t-1$ should be decreased).

The result is that if a consistent sequence of stimuli predicts reward, this system will learn the sequence, with the TD error teaching the system about earlier and earlier consistent predictors with each iteration. As the critic learns about future rewards, it is able to teach the actor to act on the basis of them. Thus the system exemplifies S-R learning with an enhanced ability to act on the basis of future reward. It has been of particular neurobiological interest since the firing of midbrain dopamine (DA) neurons appears to correspond very closely to the TD error $\delta$ (Daw \& Touretzky, 2002; McClure, Daw, \&
Montague, 2003; Schultz, 1998; Schultz, Dayan, \& Montague, 1997; Schultz \& Dickinson, 2000; Schultz, Tremblay, \& Hollerman, 1998), and other components of the basal ganglia innervated by midbrain DA neurons have been proposed to correspond to the actor and critic, be those components the matrix and striosome compartments of the striatum (Houk et al., 1995) or the dorsal and ventral striatum (O'Doherty et al., 2004).

\subsubsection{Psychostimulants and impulsivity}

However, the original interest in the relationship between DA and impulsivity stems from the discovery that amphetamine and similar psychostimulants are an effective therapy for ADHD (Bradley, 1937). Though these drugs have many actions, they are powerful releasers of DA from storage vesicles in the terminals of dopaminergic neurons, and prevent DA re-uptake from the synaptic cleft, potentiating its action (Feldman et al., 1997). It has been proposed that many features of ADHD, including preference for immediate reinforcement and hyperactivity on simple reinforcement schedules, are due to abnormally steep temporal discounting, and that this is due to a hypofunctional nucleus accumbens (Acb) DA system (Johansen, Aase, Meyer, \& Sagvolden, 2002; Sagvolden et al., 1998; Sagvolden \& Sergeant, 1998) - though whether ADHD is characterized by a hypodopaminergic or a hyperdopaminergic state, and how this and other (e.g. noradrenergic/serotonergic) abnormalities might be 'normalized' by psychostimulants is controversial (Fone \& Nutt, 2005; Russell, Sagvolden, \& Johansen, 2005; Seeman \& Madras, 2002; Solanto, 2002; Swanson, Castellanos, Murias, LaHoste, \& Kennedy, 1998; Williams \& Dayan, 2005; Zhuang et al., 2001). Many of the inferences regarding the neural abnormalities in children with ADHD have been drawn from studies of the spontaneously hypertensive rat (SHR), an inbred strain of rat that serves as an animal model of ADHD (Russell et al., 2005; Sagvolden, 2000; Sagvolden et al., 1992; Sagvolden, Pettersen, \& Larsen, 1993; Wultz, Sagvolden, Moser, \& Moser, 1990). This rat exhibits pervasive hyperactivity and attention problems that resemble ADHD, exhibits a steeper 'scallop' of responding on fixed-interval schedules of reinforcement, which can be interpreted as abnormally high sensitivity to immediate reinforcement (Sagvolden et al., 1992), is impulsive on measures of 'execution impulsivity' (Evenden \& Meyerson, 1999), and has a complex pattern of abnormalities in its DA system (Carey et al., 1998; de Villiers et al., 1995; Papa, Sagvolden, Sergeant, \& Sadile, 1996; Papa, Sergeant, \& Sadile, 1998; Russell, de Villiers, Sagvolden, Lamm, \& Taljaard, 1998; Russell, Devilliers, Sagvolden, Lamm, \& Taljaard, 1995; Russell, 2000).

Impulsive choice may reflect a lack of effectiveness of delayed reinforcement, and has been suggested to underlie at least some subtypes of ADHD (Kuntsi, Oosterlaan, \& Stevenson, 2001; Sagvolden et al., 1998; Sagvolden \& Sergeant, 1998; Sonuga-Barke, 2002). The efficacy of psychomotor stimulants in ADHD (Bradley, 1937; Solanto, 1998) suggests that they might promote the choice of delayed rewards. In fact, the effects of acute administration of psychostimulants on laboratory models of impulsive choice have varied. Some studies have found that they promote choice 
of delayed reinforcers (de Wit et al., 2002; Richards, Chock, Carlson, de Wit, \& Seiden, 1997; Richards, Sabol, \& de Wit, 1999; Sagvolden et al., 1992; Wade, de Wit, \& Richards, 2000), while others have found the opposite effect (Charrier \& Thiébot, 1996; Evenden \& Ryan, 1996; Logue et al., 1992); the same psychostimulant can even have opposite effects in different tasks designed to measure impulsivity (Richards, Chock, et al., 1997). One factor that may explain some of these discrepant effects is the presence of cues or signals present during the delay to the larger/later alternative. Such signals tend to increase responding for the delayed reinforcer (Lattal, 1987; Mazur, 1997), perhaps because they become associated with the primary reinforcer and themselves become conditioned reinforcers, thus affecting choice (Williams \& Dunn, 1991). Psychostimulants increase the effect of conditioned reinforcers (Hill, 1970; Robbins, 1976, 1978; Robbins, Watson, Gaskin, \& Ennis, 1983), and their effects in delayed reinforcement choice tasks can depend on whether explicit signals are presented during the delay (Cardinal, Robbins, \& Everitt, 2000). However, conditioned reinforcement is certainly not the only procedural difference between studies that have found differing effects of psychostimulants.

\subsubsection{Dopamine $D_{1}$ and $D_{2}$ receptors and impulsivity}

It should also be emphasized that few studies of the effects of psychostimulants on impulsive choice have addressed the pharmacological basis of their effects. Some of the effects may indeed not be dopaminergic: for example, the effects of amphetamine may depend in part on 5-HT (Winstanley et al., 2003). However, Wade et al. (2000) have shown that mixed or $\mathrm{D}_{2}$-type $\mathrm{DA}$ receptor antagonists induce impulsive choice, while $\mathrm{D}_{1}$-type receptor antagonists do not, suggesting that $\mathrm{DA} \mathrm{D}_{2}$ receptors normally promote choice of delayed reinforcement.

The role of DA in reward uncertainty is also not clear-cut. DA neurons respond to reward prediction errors with changes in their phasic firing rate, as discussed above, and may also carry information in their sustained firing rate specifically about reward uncertainty (Fiorillo, Tobler, \& Schultz, 2003, 2005; Niv, Duff, \& Dayan, 2005; Tobler, Fiorillo, \& Schultz, 2005), but little is known of the causal role of DA in choice involving uncertain rewards.

\subsection{Relationship between addictive drugs and impulsivity}

Given that impulsivity is part of the syndrome of drug addiction, with impulsive choice playing a prominent role in maintaining the selection of drugs of abuse in favour of other, longer-term rewards (APA, 2000; Bickel et al., 1999; Evenden, 1999a; Heyman, 1996; Mitchell, 1999; Poulos et al., 1995), the relationship between addictive drugs and impulsive choice is of clear interest. Studies examining discounting in addicts have focused primarily on delay, rather than uncertainty discounting (see Mitchell (2003, 2004a, 2004b)). There is little evidence for differences in uncertainty discounting among smokers (Mitchell, 1999) or alcohol abusers (Vuchinich \& Calamas, 1997), though alcohol has been shown to modify decision making under uncertainty (George, Rogers, \& Duka, 2005). However, decision-making deficits in risk taking and gambling tasks have been demonstrated in opiate and amphetamine users (Ersche et al., 2005; Leland \& Paulus, 2005; Rogers, Everitt, et al., 1999). The fact that the deficits were in some cases correlated with the number of years of abuse suggests (but does not prove) that the deficits were drug induced; the possibility remains that the decision-making deficits predated and predisposed to the addiction.

Abnormally steep delay discounting has been demonstrated in drug addicts, including alcoholics (Petry, 2001; Vuchinich \& Calamas, 1997), cocaine users (Coffey, Gudleski, Saladin, \& Brady, 2003; Kirby \& Petry, 2004), opiate users (Kirby \& Petry, 2004; Kirby, Petry, \& Bickel, 1999; Madden, Petry, Badger, \& Bickel, 1997), and smokers (Bickel et al., 1999; Mitchell, 1999, 2003; Ohmura, Takahashi, \& Kitamura, 2005; Reynolds et al., 2004); again, the question of cause and effect is hard to determine, although steeper discounting in current addicts compared to ex-addicts again raises the possibility of an effect of ongoing drug use. Many studies have looked at the pharmacological effects of addictive drugs on measures of impulsivity including response inhibition; rather fewer have looked specifically at delay and/or probability discounting in a formal experimental (causal) design. Chronic cocaine administration transiently increases delay discounting (increases impulsive choice) in rats (Paine, Dringenberg, \& Olmstead, 2003), as does acute morphine administration (Kieres et al., 2004); acute administration of psychostimulants was discussed above, and chronic methamphetamine has been shown to increase impulsive choice in rats (Richards, Sabol, et al., 1999). In keeping with everyday experience, alcohol has been observed to increase risk taking (Lane, Cherek, Pietras, $\&$ Tcheremissine, 2004). However, the findings for a given drug have not always been consistent. For example, Ortner, MacDonald, and Olmstead (2003) recently found that alcohol reduced delay discounting in humans, while Richards, Zhang, et al. (1999) found no effect of alcohol on this measure, and several investigators have found impulsive choice to be induced by alcohol in rats (Evenden \& Ryan, 1999; Tomie, Aguado, Pohorecky, \& Benjamin, 1998). These discrepancies may in some cases be because the drugs (or the state of addiction) do not have a unitary effect on discounting, but one which depends heavily on the situation and the particular choices involved. For example, Mitchell has shown that cigarette deprivation increases choice impulsivity when decisions concern cigarettes, but not when they concern money (Mitchell, 2004a); likewise, smokers temporally discount cigarettes more than money (Bickel et al., 1999), as well as discounting money more than controls; opiate abusers discount opiates more than money (Madden, Bickel, \& Jacobs, 1999), and cocaine users discount cocaine more than money (Coffey et al., 2003).

\section{Neuroanatomically specific studies}

In recent years, a number of studies have examined the effects of focal excitotoxic or neurochemical lesions on choice and learning involving delayed or uncertain rewards, 


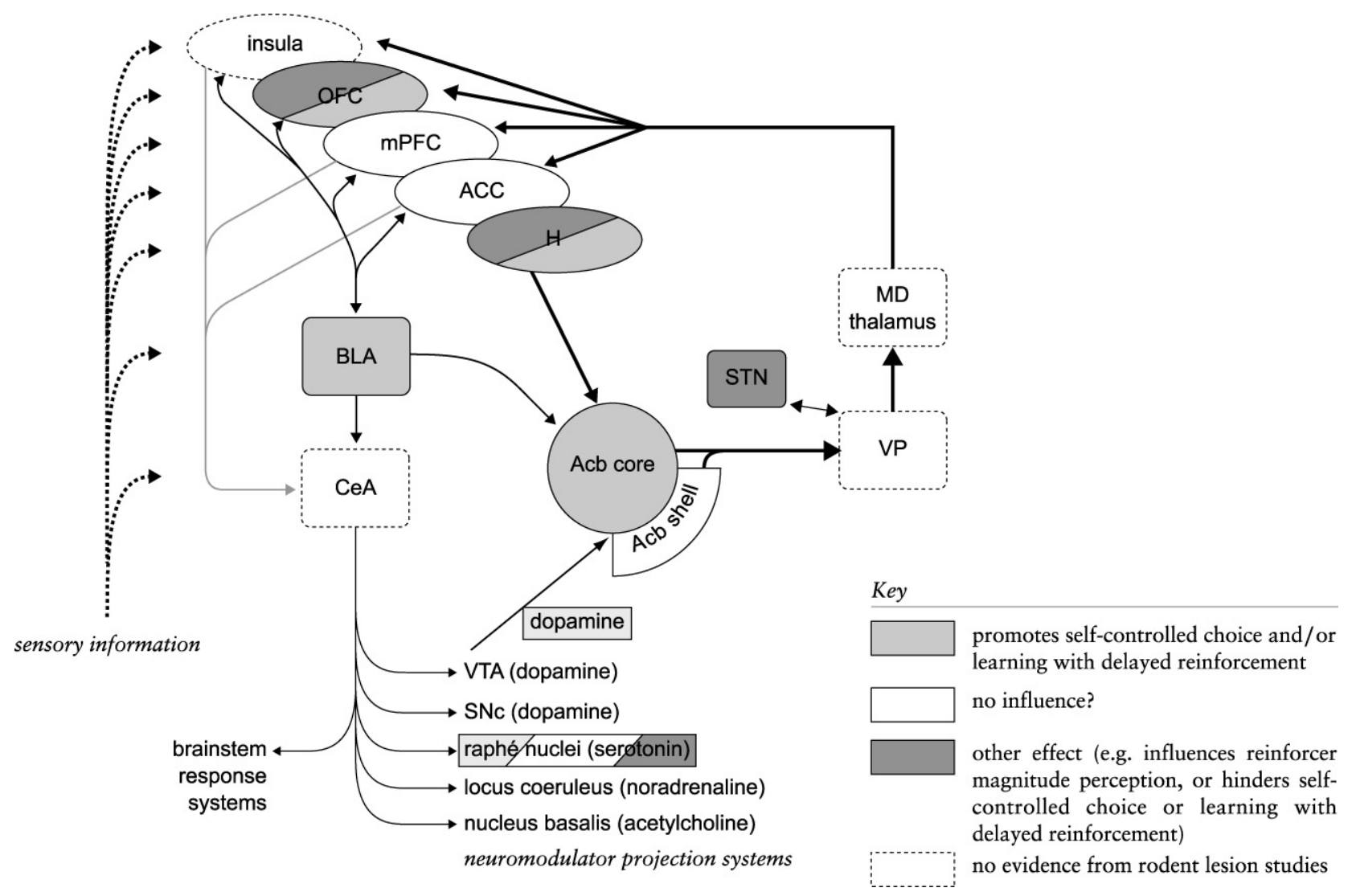

Fig. 2. Schematic of the limbic corticostriatal loop (after Cardinal, Parkinson, Hall, et al., 2002), showing key structures and their apparent influence on selfcontrolled choice (ability to tolerate delays to reward) as suggested by lesion studies in the rat. OFC, orbitofrontal cortex; mPFC, medial prefrontal cortex (prelimbic/infralimbic cortex in the rat); ACC, anterior cingulate cortex; H, hippocampal formation; BLA, basolateral amygdala; CeA, central nucleus of the amygdala; Acb, nucleus accumbens; STN, subthalamic nucleus; VP, ventral pallidum; MD, mediodorsal; VTA, ventral tegmental area; SNc, substantia nigra pars compacta. Not all structures and connections are shown; for example, there are projections from prefrontal cortical regions, including the OFC, to the STN (Berendse \& Groenewegen, 1991; Hamani et al., 2004; Maurice et al., 1998).

in additional to correlational studies using functional imaging, microdialysis, and electrophysiology. These studies centre on interconnected structures forming part of the limbic corticostriatal loop (Fig. 2).

\subsection{Nucleus accumbens core (AcbC)}

\subsubsection{Choice involving delayed reinforcement}

The Acb responds to anticipated rewards in humans, other primates, chicks, and rats (Bjork et al., 2004; Breiter, Aharon, Kahneman, Dale, \& Shizgal, 2001; Cromwell \& Schultz, 2003; Izawa, Aoki, \& Matsushima, 2005; Knutson, Adams, Fong, \& Hommer, 2001; Martin \& Ono, 2000; Miyazaki, Mogi, Araki, \& Matsumoto, 1998; Schultz, Apicella, Scarnati, \& Ljungberg, 1992; Schultz, Tremblay, \& Hollerman, 2000). It is innervated by dopamine (DA) neurons that respond to errors in reward prediction in a manner appropriate for a teaching signal (Schultz, 1998; Schultz et al., 1997; Schultz \& Dickinson, 2000; Schultz et al., 1998), as discussed above, and interventional studies have shown it to be a key site for the motivational impact of impending rewards (reviewed by Cardinal, Parkinson, Hall, et al. (2002), Everitt et al. (1999), Parkinson, Cardinal, and Everitt (2000), Robbins et al. (2005), Robbins and Everitt (1996), Salamone, Cousins, and Snyder (1997)). Acb abnormalities have also been observed in rat models of ADHD (Carey et al., 1998; de Villiers et al., 1995; Papa et al., 1996, 1998; Russell et al., 1998; Russell, 2000; Sadile, 2000). Causal experimental studies have shown that lesions of the AcbC produce impulsive choice, reducing rats' preference for large/delayed rewards, compared to small/immediate rewards (Cardinal, Pennicott, Sugathapala, Robbins, \& Everitt, 2001; Cardinal, Robbins, et al., 2003; Cardinal, Parkinson, et al., 2003). Similar effects are observed following lesions of the caudal lobus parolfactorius in the chick, thought to be the avian counterpart of the Acb (Izawa, Zachar, Yanagihara, \& Matsushima, 2003).

Recently, AcbC lesions have also been found to impair performance on a task requiring rats to choose between an uncertain immediate reward and a certain delayed reward (Pothuizen, Jongen-Relo, Feldon, \& Yee, 2005). One alternative required completion of a fixed-ratio-5 (FR5) response for immediate delivery of a food pellet with probability $P=0.25$; the other required completion of an FR5 response for delayed certain delivery of an identical food pellet. AcbC lesions reduced rats' preference for the delayed, certain alternative, following sustained testing (Pothuizen et al., 2005). AcbC lesions also reduced efficiency (the number of responses made per reward earned) in a differential-reinforcement-oflow-rates (DRL) schedule (Pothuizen et al., 2005), in which 
animals must respond below a certain rate in order to obtain reward. This is much like the effects of whole-Acb lesions (Reading \& Dunnett, 1995), although the DRL task may also be susceptible to general levels of motor activity: AcbC-lesioned rats are hyperactive (Cardinal \& Cheung, 2005; Cardinal et al., 2001; Maldonado-Irizarry \& Kelley, 1995; Parkinson, Olmstead, Burns, Robbins, \& Everitt, 1999), and hyperactivity would itself tend to reduce DRL efficiency.

\subsubsection{Processing of reward magnitude}

Is the impulsive choice seen in AcbC-lesioned rats (Cardinal et al., 2001) due to an effect on subjects' processing of reward delay, or of reward magnitude? Impulsive choice might arise as a result either of altered sensitivity to reinforcer magnitude, or delay, or both (Ho et al., 1999). Lesioned rats might have chosen the immediate small reward because they did not perceive the large reward to be as large (relative to the small reward) as sham-operated controls did, in which case the abnormally low magnitude of the large reward would be insufficient to offset the normal effects of the delay. Alternatively, they might have perceived the reward magnitudes normally, but been hypersensitive to the delay. The latter explanation-hypersensitivity to the effects of the delayappears more likely. In the delayed reinforcement choice task used, based on that of Evenden and Ryan (1996), rats were offered regular choices, in discrete trials, between a single immediate food pellet and four pellets delivered with a delay that varied from 0 to $60 \mathrm{~s}$, increasing in stages across the session. AcbC lesions also reduced preference for the large reinforcer somewhat at zero delay (Cardinal et al., 2001), but this was probably due to a task artefact, namely within-session generalization from trials in which delays were present (Cardinal et al., 2000), since prolonged training in the absence of delays restored a near-absolute preference for the large reinforcer in the majority of subjects, who were then much more impulsive than shams again when delays were re-introduced (Cardinal, Robbins, et al., 2003). These results indicate that AcbC-lesioned rats were able to discriminate the two reinforcers' magnitudes, but preferred immediate small rewards to larger delayed rewards.

Further evidence indicates that the processing of reward magnitude is quantitatively normal in AcbC-lesioned rats. Excitotoxic lesions of the whole Acb do not prevent rats from detecting changes in reward value (induced either by altering the concentration of a sucrose reward or by changing the deprivational state of the subject) (Balleine \& Killcross, 1994). Such lesions also do not impair rats' ability to respond faster when environmental cues predict the availability of larger rewards (Brown \& Bowman, 1995), and nor does inactivation of the Acb with local anaesthetic or blockade of AMPA glutamate receptors in the Acb (Giertler, Bohn, \& Hauber, 2004); the effects of intra-Acb NMDA receptor antagonists have varied (Giertler, Bohn, \& Hauber, 2003; Hauber, Bohn, \& Giertler, 2000). AcbC-lesioned rats can still discriminate large from small rewards (Cardinal, Robbins, et al., 2003; Cardinal et al., 2004). Similarly, DA depletion of the Acb does not affect the ability to discriminate large from small reinforcers (Cousins, Atherton, Turner, \& Salamone, 1996; Salamone, Cousins, \& Bucher, 1994; Salamone, Wisniecki, Carlson, \& Correa, 2001), and systemic DA antagonists do not affect the perceived quantity of food as assessed in a psychophysical procedure (Martin-Iverson, Wilkie, \& Fibiger, 1987). Excitotoxic AcbC lesions do not impair rats' ability to allocate their responses across two schedules in proportion to the experienced reinforcement rate, even when the two schedules are identical except in the magnitude of the reinforcements they provide, suggesting their sensitivity to reinforcer magnitude is quantitatively no worse than shams' (Cardinal \& Cheung, 2005).

The observation that AcbC lesions reduce preference for delayed, certain rewards (Pothuizen et al., 2005) as well as delayed, large rewards (Cardinal et al., 2001), also supports the assertion that AcbC-lesioned animals have impaired tolerance for delays, and that the effects are not due simply to effects on reward magnitude processing - particularly given evidence that AcbC lesions have been observed to reduce preference for large, uncertain rewards (discussed below).

\subsubsection{Learning with delayed reinforcement}

Excitotoxic lesions of the AcbC do not prevent rats from learning a simple instrumental response when the reinforcing outcome follows their action immediately (Cardinal \& Cheung, 2005). However, AcbC lesions impair rats' ability to learn the same instrumental response when the outcome is delayed by 10 or $20 \mathrm{~s}$ (Cardinal \& Cheung, 2005). Increasing delays impaired learning in normal rats to some degree, which is a well-known finding (Dickinson et al., 1992; Grice, 1948; Lattal \& Gleeson, 1990). Rats with AcbC lesions were unimpaired (compared to sham-operated controls) when there was no delay, but were profoundly impaired when there was a delay between action and outcome, compared to shams learning with the same delay (Cardinal \& Cheung, 2005). AcbC lesions also impaired performance of an instrumental response that was learned preoperatively, but again only when response-reinforcer delays were present.

The fact that pre-exposure to the context improves instrumental learning in normal rats (Dickinson et al., 1992) suggests one possible mechanism by which AcbC lesions might retard learning when delays are present. When a reinforcer arrives, it may be associated either with a preceding response, or with the context. Therefore, in normal animals, pre-exposure to the context may retard the formation of context-reinforcer associations by latent inhibition, or it might serve to retard the formation of associations between irrelevant behaviours and reinforcement. Similarly, non-reinforced exposure to the context forces the subjects to experience a zero-response, zeroreinforcer situation, i.e. $P$ (outcome $\mid$ no action $)=0$. When they are then exposed to the instrumental contingency, such that $P$ (outcome $\mid$ action) $>0$, this prior experience may enhance their ability to detect the instrumental contingency $\Delta P=P($ outcome $\mid$ action $)-P($ outcome $\mid$ no action $)$. In one aversive Pavlovian conditioning procedure in which a conditioned stimulus (CS) was paired with electric shock, AcbC lesions have been shown to impair conditioning to 
discrete CSs, but simultaneously to enhance conditioning to contextual (background) CSs (Parkinson, Robbins, \& Everitt, 1999), though not all behavioural paradigms show this effect (Jongen-Relo, Kaufmann, \& Feldon, 2003; Levita, Dalley, \& Robbins, 2002). It is therefore possible that enhanced formation of context-reinforcer associations may explain the retardation of response-reinforcer learning in AcbC-lesioned rats in the presence of delays.

Acb lesions have also produced delay-dependent impairments in a delayed-matching-to-position task (Dunnett, 1990; Reading \& Dunnett, 1991); their effects on the delayedmatching-to-sample paradigm have also been studied, but a more profound and delay-independent deficit was observed, likely due to differences in the specific task used (Burk \& Mair, 2001).

\subsubsection{Choice involving uncertain reward}

Correlational studies have also suggested that the Acb may also be involved in the processing of uncertain or probabilistic reinforcement. DA neurons that innervate the Acb may fire in a manner related to reward probability (Fiorillo et al., 2003, 2005; Niv et al., 2005; Tobler et al., 2005) and the midbrain, the site of the cell bodies of these neurons, responds to stimulus uncertainty in humans (Aron et al., 2004). A greater blood flow response is observed in the human Acb during the selection of high-reward/high-risk options, compared to lowreward/low-risk outcomes, in a task where the risk is of not winning (Ernst et al., 2004), with similar activation to highreward/high-risk option selection in a task where the risk is of losing (Matthews, Simmons, Lane, \& Paulus, 2004); this latter activation was correlated with personality measures of harm avoidance. Likewise, an increase in Acb blood flow preceded risk-taking decisions in a financial game with human subjects (Kuhnen \& Knutson, 2005).

Excitotoxic lesions of the AcbC have been shown to induce risk-averse choice in rats (Cardinal \& Howes, 2005). AcbC lesions did not prevent rats from discriminating a large reward from a small reward, or a certain reward from an uncertain reward. However, when offered the choice between a small/certain reward and a large/uncertain reward, AcbC-lesioned rats showed a reduced preference for the large/uncertain reward (compared to sham-operated controls) in their final pattern of postoperative choice. AcbC-lesioned rats exhibited a tendency to behave as if an uncertain outcome were less likely than was really the case. In another study, AcbC lesions reduced preference for delayed, certain rewards (Pothuizen et al., 2005), but this does not specifically address the contribution of the AcbC to choosing rewards based on their certainty, particularly as there is now evidence from a number of very different tasks that AcbC lesions impair the processing of delayed reinforcement (Cardinal \& Cheung, 2005; Cardinal et al., 2001; Pothuizen et al., 2005). In sum, together with studies examining the effects of AcbC lesions on delayed reinforcement, these results suggest that the AcbC contributes to reinforcement and choice particularly when the reinforcer is temporally distant or uncertain.

\subsubsection{Relationship to neuromodulator function}

The Acb is innervated by the a number of neuromodulator systems, including 5-HT (see Halliday, Harding, and Paxinos (1995)) and DA (Fallon \& Loughlin, 1995; Ungerstedt, 1971). The DA projection to the Acb is prominent, but although systemic $\mathrm{D}_{2}$-type DA receptor antagonists can induce impulsive choice involving delayed reinforcement (Wade et al., 2000), this effect may not depend critically on DA in the Acb. Intra-Acb $\mathrm{D}_{1}$ and $\mathrm{D}_{2}$ receptor antagonists do not affect rats' ability to wait for reward in a cued progressive delay task (Wakabayashi, Fields, \& Nicola, 2004), and DA depletion of the Acb using the toxin 6-hydroxydopamine (6-OHDA) appears not to affect delay discounting directly, though it modifies the effect of systemic $5-\mathrm{HT}_{1 \mathrm{~A}}$ receptor agonists on choice between $\mathrm{SS}$ and LL rewards (Winstanley, Theobald, Dalley, \& Robbins, 2005). The Acb does not receive a substantial NA innervation (AstonJones, Shipley, \& Grzanna, 1995).

\subsubsection{Integration of AcbC functions with respect to impulsivity}

Impulsivity is multifaceted, reflecting individual differences in distinct processes involving information gathering, the selection of outcomes, and the inhibition of motor actions (Evenden, 1999b). Furthermore, delay discounting and probability discounting may also reflect separate processes contributing to the selection of outcomes, as discussed above. Damage to the AcbC can produce impulsive choice, an impaired ability to choose delayed rewards (Cardinal et al., 2001; Pothuizen et al., 2005), in addition to hyperactivity (Cardinal \& Cheung, 2005; Cardinal et al., 2001; Maldonado-Irizarry \& Kelley, 1995; Parkinson, Olmstead, et al., 1999), though without impairments in attentional function (Christakou, Robbins, \& Everitt, 2004; Cole \& Robbins, 1989) and without motoric impulsivity as assessed by the stop-signal task (Eagle \& Robbins, 2003). Destruction of the AcbC does not, therefore, mimic all the signs of ADHD, but these findings suggest that the behaviour of rats with AcbC damage resembles that of humans with the hyperactive-impulsive subtype of ADHD (APA, 2000). In the context of choice involving uncertain appetitive reinforcement, 'impulsivity' would equate to risk taking (less steep uncertainty discounting or greater willingness to choose unlikely rewards). AcbC lesions, however, have produced a risk-averse or conservative pattern of choice (Cardinal \& Howes, 2005). Clearly, then, AcbC-lesioned rats cannot be characterized as impulsive in all senses. A more appropriate unifying concept would seem to be that the AcbC promotes the selection, and perhaps the salience, of uncertain and delayed rewards-perhaps, in general, of rewards that are not certain, imminent, or present (Cardinal, Parkinson, Hall, et al., 2002). The AcbC promotes choice of, and learning with, delayed rewards (Cardinal \& Cheung, 2005; Cardinal et al., 2001; Pothuizen et al., 2005). It appears to promote the selection of uncertain reinforcers (Cardinal \& Howes, 2005), and this is compatible with human imaging studies showing increased Acb blood flow during the selection of high-risk options (Ernst et al., 2004; Kuhnen \& Knutson, 2005; Matthews et al., 2004). The Acb is required for Pavlovian-instrumental transfer (PIT), the process by which Pavlovian CSs signalling reward 
enhance instrumental responding for those rewards (de Borchgrave, Rawlins, Dickinson, \& Balleine, 2002; Hall, Parkinson, Connor, Dickinson, \& Everitt, 2001). It is also required for autoshaping, or locomotor approach to appetitive Pavlovian CSs (Cardinal, Parkinson, Lachenal, et al., 2002; Parkinson et al., 2002; Parkinson, Olmstead, et al., 1999; Parkinson, Robbins, et al., 1999; Parkinson, Willoughby, et al., 2000), and it influences conditioned reinforcement, the process of working for CSs previously paired with reinforcement (Cador, Taylor, \& Robbins, 1991; Parkinson, Olmstead, et al., 1999; Taylor \& Robbins, 1984, 1986). Acb DA also contributes to subjects' motivation to work hard (Ikemoto \& Panksepp, 1999; Mingote, Weber, Ishiwari, Correa, \& Salamone, 2005; Salamone \& Correa, 2002; Salamone, Correa, Mingote, \& Weber, 2003, 2005).

What would one expect in an aversive context? It would be expected that increased odds/uncertainty/probability discounting-effectively, a tendency to behave as if an uncertain outcome were less likely than it really iswould produce risk aversion for appetitive outcomes (reduced willingness to choose large, unlikely rewards) but risk proneness for aversive outcomes (increased willingness to choose large, uncertain punishments over small, certain punishments) (Ho et al., 1999). Similarly, enhanced delay discounting would produce impulsive choice in an aversive context, impairing the ability to choose a small immediate penalty in preference to a large delayed penalty. In humans, at least, the delay and probability discounting processes appear similar for rewards and losses (Green \& Myerson, 2004; Ostaszewski \& Karzel, 2002). At present, it is not known whether AcbC lesions also affect choice involving delayed or uncertain outcomes in an aversive context; however, it is clear that the Acb is involved in aversive motivation (Parkinson, Robbins, et al., 1999; Salamone, 1994).

\subsection{Nucleus accumbens shell (AcbSh)}

In contrast to the effects of AcbC lesions on choice between delayed, certain and immediate, uncertain rewards, AcbSh lesions have been shown to have effects neither on this task nor on DRL efficiency (Pothuizen et al., 2005). The AcbSh responds to a variety of unconditioned stimuli (Bassareo \& Di Chiara, 1999; Ito, Dalley, Howes, Robbins, \& Everitt, 2000) and has a role in the hedonic assessment of rewards (Berridge, 2000; Kelley \& Berridge, 2002). It plays a role in latent inhibition (Pothuizen et al., 2005; Pothuizen, Jongen-Relo, Feldon, \& Yee, 2006), and influences unlearned behaviours including feeding (Basso \& Kelley, 1999; Kelley, 1999; Kelley \& Swanson, 1997; Stratford \& Kelley, 1997) and locomotion (Parkinson, Olmstead, et al., 1999; Swanson, Heath, Stratford, \& Kelley, 1997). The AcbSh has also been shown to be abnormal in animal models of ADHD (Carey et al., 1998; Papa et al., 1996, 1998; Sadile, 2000). However, these results suggest it does not contribute to choice involving delayed or uncertain rewards (Pothuizen et al., 2005).

\subsection{Orbitofrontal cortex $(\mathrm{OFC})$}

The OFC is a region of the PFC that projects to the AcbC and is strongly implicated in the assessment of reward value.
Mobini et al. (2002) recently found that lesions encompassing the OFC induced impulsive choice in a discrete-trial SS/LL reward choice task very similar to that described above. As before, results from this simple form of task do not indicate whether the impulsive choice was as a result of altered sensitivity to reinforcer magnitude or delay. Although these lesions damaged prelimbic cortex (PrL) in addition to the OFC (Mobini et al., 2002), the hypothesis that OFC damage was responsible for the behavioural effect is strengthened by the finding that medial prefrontal cortex (mPFC) lesions encompassing PrL do not induce impulsive choice (Cardinal et al., 2001). In contrast, Winstanley, Theobald, Cardinal, and Robbins (2004) recently found that OFC lesions induced the opposite effect-better self-control than shams-in exactly the task described above (Cardinal et al., 2001). One possible reason for this discrepancy is that subjects in the study by Winstanley et al. were trained before the OFC was destroyed and retested postoperatively, while Mobini et al. trained and tested postoperatively. Another is that Mobini et al. (2002) offered rats a choice between a one-pellet immediate reinforcer and a two-pellet delayed reinforcer, whereas Winstanley, Theobald, Cardinal, et al. (2004) used a one-pellet immediate reinforcer and a four-pellet delayed reinforcer. Differences in subjects' sensitivity to either the delay or the magnitude of reinforcement can play a role in determining preference in this task (Cardinal, Robbins, et al., 2003; Ho et al., 1999; Mobini et al., 2002) and it may be that OFC lesions affect both, increasing both the delay discounting parameter $K$ and the magnitude discounting parameter $Q$ (Mobini et al., 2002). An increase in $K$ would imply steeper delay discounting; an increase in $Q$ would imply an increase in sensitivity to the ratio of the magnitudes of the two reinforcers, and could mask (or potentially reverse) the increase in impulsivity produced by the increase in $K$. There is direct support for this hypothesis: OFC lesions appear to increase $K$, the rate of delay discounting, as well as increasing the magnitude sensitivity parameter $Q$ (Kheramin et al., 2003, 2002). The same effect of increases in both $K$ and $Q$ has been observed with DA-depleting OFC lesions (Kheramin et al., 2004). This emphasizes the necessity for quantitative analysis of delay and magnitude sensitivity (Ho et al., 1999) or the use of multiple, very different paradigms to provide independent measurements of sensitivity to delay and magnitude (Cardinal, Robbins, et al., 2003). It also reminds us of an important clinical point: faced with steep delay discounting in a task involving choice between SS and LL rewards, increasing the ratio of the large to the small reward may ameliorate the impulsivity.

As discussed above, it has been suggested that hyperbolic discounting is explicable as the overall effect of two or more different systems, such as an explicit (declarative) system that exhibits minimal or exponential discounting, plus phenomena that make rewards more salient and promote their choice when they are immediately available. Recently, such a twofactor model was used in the analysis of a human functional magnetic resonance imaging study of choice involving rewards differing in magnitude and delays, with delays ranging from less than a day to 6 weeks (McClure, Laibson, Loewenstein, 
\& Cohen, 2004). Lateral prefrontal and intraparietal cortical regions were activated independently of the delay, and were suggested to be part of a system that evaluates both immediate and delayed rewards according to a 'rational' (meaning non-hyperbolic) temporal discounting system, while limbic regions including the ventral striatum and medial OFC were preferentially activated by the relatively immediate rewards, and were suggested to be part of a system that promotes the choice of imminent rewards without consideration of delayed alternatives. These limbic regions were more likely to be activated than the 'delay-independent' areas on trials in which an earlier reward was chosen. This would sit neatly with studies showing that OFC lesions reduce impulsive choice (Winstanley, Theobald, Cardinal, et al., 2004); however, it does not square so easily with rodent evidence showing that destruction of the AcbC (part of the ventral striatum) or the OFC enhances delay discounting, meaning that delayed alternatives are less likely to be chosen (Cardinal et al., 2001; Kheramin et al., 2003, 2002; Mobini et al., 2002).

The PFC, which projects heavily to the AcbC (Brog, Salyapongse, Deutch, \& Zahm, 1993), is also involved in decision making under conditions of uncertainty. Humans with orbitofrontal cortex (OFC) or ventromedial PFC damage are impaired on the Iowa gambling task (Bechara et al., 1994; Bechara, Damasio, Tranel, \& Damasio, 1997; Bechara, Tranel, Damasio, \& Damasio, 1996), in which subjects must learn to differentiate between low-reward, low-risk card decks that yield a net positive outcome and high-reward, high-risk decks that yield a net negative outcome, though the precise locus and nature of the deficit seen on this task is debated (Clark, Manes, Antoun, Sahakian, \& Robbins, 2003; Fellows \& Farah, 2005; Manes et al., 2002). OFC neurons respond to reward expectancy (see Hikosaka and Watanabe (2000)). Choice between small, likely rewards and large, unlikely rewards increases cerebral blood flow in orbital and inferior PFC (Ernst et al., 2004; Rogers, Owen, et al., 1999; Rogers, Ramnani, et al., 2004), and OFC damage also impairs performance of a task requiring human subjects to choose between two possible outcomes and to bet on their choice, with lesioned subjects deciding slowly and failing to choose the optimal, most likely outcome (Rogers, Everitt, et al., 1999). Excitotoxic lesions of the OFC make rats less likely than sham-operated controls to choose a large, uncertain reward over a small, certain reward (Mobini et al., 2002); OFC-lesioned rats had lower indifference odds (higher indifference probabilities; steeper uncertainty discounting) and exhibited risk-averse choice, akin to AcbC-lesioned subjects, as described above. As discussed above, there is direct evidence that excitotoxic OFC lesions and OFC DA depletion do alter sensitivity to the relative magnitudes of the two rewards (Kheramin et al., 2005, 2004), but the effect of steepening uncertainty discounting (of increasing the odds discounting parameter $H$ ) is present in addition to the effects on reinforcer magnitude sensitivity (Kheramin et al., 2003).

\subsection{Basolateral amygdala (BLA)}

The basolateral amygdala (BLA) also projects to the AcbC, and has extensive reciprocal connections with the OFC.
Excitotoxic lesions of the BLA promote impulsive choice in a task involving choice between an immediate one-pellet reward and a delayed four-pellet reward (Winstanley, Theobald, Cardinal, et al., 2004), similar to the effects of AcbC lesions (Cardinal et al., 2001) but opposite to those of OFC lesions in the same task (Winstanley, Theobald, Cardinal, et al., 2004). Although this study is notable for finding opposite effects of BLA and OFC lesions, which is unusual (see also Izquierdo and Murray (2005)), the explanation for this effect is unclear. One obvious possibility, given the effects of OFC lesions to increase both the delay discounting parameter $K$ and the magnitude sensitivity parameter $Q$ (in the model of Ho et al. (1999)), is that BLA lesions and AcbC lesions simply increase $K$ without affecting $Q$. There is indirect evidence for this in the case of AcbC lesions, discussed above; for the BLA, this hypothesis remains untested. Some studies have demonstrated deficits following amygdala inactivation when reward size is suddenly changed (Coleman-Mesches, Salinas, \& McGaugh, 1996; Liao \& Chuang, 2003; Salinas, IntroiniCollison, Dalmaz, \& McGaugh, 1997; Salinas \& McGaugh, 1996; Salinas, Packard, \& McGaugh, 1993), though changing the size of a reward for performing the same task has obvious emotional significance and the amygdala is well known to be involved in affective representation (see Aggleton (2000) and Cardinal, Parkinson, Hall, et al. (2002)). One study has found deficits in memory for reinforcer magnitude following amygdala lesions, even if this was not a primary deficit in reinforcer magnitude discrimination (Kesner \& Williams, 1995). None of these bear directly on the question of whether relative reinforcer magnitude discrimination (as measured by $Q$ ) is altered by BLA lesions.

\subsection{Anterior cingulate cortex (ACC)}

Excitotoxic lesions of the ACC have no effect on choice between SS and LL rewards in rats (Cardinal et al., 2001), indicating that the ACC is not required for normal choice of delayed reinforcement. These results suggest that ACC dysfunction is not an important contributor to impulsive choice, despite the involvement of the ACC in reward-related learning (Bussey, Everitt, \& Robbins, 1997; Bussey, Muir, Everitt, \& Robbins, 1997; Cardinal, Parkinson, et al., 2003; Parkinson, Willoughby, et al., 2000) and findings of ACC abnormalities in ADHD (Bush et al., 1999; Rubia et al., 1999). However, ACC lesions do impair choice between small/sooner/low-effort and large/later/high-effort alternatives, reducing preference for the high-effort option (Walton, Bannerman, Alterescu, \& Rushworth, 2003; Walton, Bannerman, \& Rushworth, 2002), indicating that the ACC is involved in promoting the selection of effortful alternatives. The DA innervation of the ACC does not appear important for this function (Walton, Croxson, Rushworth, \& Bannerman, 2005).

However, ACC lesions can make rats motorically impulsive (leading to simple disinhibition, or 'execution' impulsivity). ACC-lesioned rats have been found to over-respond to unrewarded stimuli (Bussey, Everitt, et al., 1997; Parkinson, Willoughby, et al., 2000) and to respond prematurely in 
situations where they are required to wait (Muir, Everitt, \& Robbins, 1996). They also exhibit discriminative deficits in Pavlovian conditioning tasks (Cardinal, Parkinson, et al., 2003), though the full range of functions associated with the ACC (including error detection, attentional control, and mood; see Cardinal, Parkinson, Hall, et al. (2002)) is beyond the scope of this review.

The contribution of the ACC to probabilistic choice is less clear. In both humans and rhesus monkeys, the ACC responds to anticipated gain in tasks in which rewards of different magnitudes are available with varying probabilities. In the rhesus monkey, the ACC responds to some combination of reward size and reward probability (Amiez, Joseph, \& Procyk, 2005a) and deactivation of the ACC impairs such choices (Amiez, Joseph, \& Procyk, 2005b), but human studies would suggest that the ACC responds to the magnitude rather than the probability of expected gains (Rogers, Ramnani, et al., 2004). However, a nearby region of human medial prefrontal cortex has been observed to respond to reward probability (Knutson, Taylor, Kaufman, Peterson, \& Glover, 2005).

\subsection{Prelimbic (PrL) and infralimbic (IL) cortex}

The mPFC projects to the AcbC, is involved in rewardrelated learning (e.g. Balleine and Dickinson (1998), Bechara, Damasio, Damasio, and Lee (1999), Richardson and Gratton (1998) and Tzschentke (2000)), receives DA and 5-HT input (see Fallon and Loughlin (1995) and Halliday et al. (1995)), and has been observed to be abnormal in ADHD (Ernst, Zametkin, Matochik, Jons, \& Cohen, 1998; Rubia et al., 1999). However, lesions of the rat $\mathrm{mPFC}$, primarily PrL and infralimbic (IL) cortex, had no delay-specific effects on choice between large/delayed and small/immediate rewards (Cardinal et al., 2001); the effects observed appeared to be task-specific, related to an insensitivity to the contingencies or stimuli present in the task, perhaps as a result of a loss of temporal discriminative stimulus control (Cardinal, Robbins, et al., 2003). It is important to note that PrL may have more functional homology to the primate dorsolateral prefrontal cortex than to regions that are medial within human PFC (Uylings, Groenewegen, \& Kolb, 2003). Aspirative lesions of the mPFC have previously been shown to induce a deficit in timing ability in rats (Dietrich \& Allen, 1998), with impaired temporal discrimination in the peak procedure, an operant task that assesses the ability to time a stimulus (Catania, 1970; Roberts, 1981). Consistent with the view that rodent mPFC lesions do not affect the basic process of choosing between reinforcers of different value, combined PrL/IL lesions did not affect choice between small/low-effort and large/high-effort alternatives in the task of Walton et al. (2003).

\subsection{Insula}

A further cortical region that may be involved in decisions involving uncertainty is the insula, or insular cortex. Anterior insula activation has been observed to precede risk-averse choice in humans (Kuhnen \& Knutson, 2005), in a task in which
Acb activation preceded risk-prone choice. The authors suggest that in tasks such as these, the Acb represents predictions of gain (Knutson et al., 2001), while the insula represents predictions of loss (see also Paulus, Rogalsky, Simmons, Feinstein, and Stein (2003)); activation in both structures is related to personality measures of harm avoidance (Paulus et al., 2003; Matthews et al., 2004).

\subsection{Subthalamic nucleus (STN)}

The subthalamic nucleus (STN) is a component of the basal ganglia that receives projections both from the globus pallidus (pallidum) and the cerebral cortex (Hamani, SaintCyr, Fraser, Kaplitt, \& Lozano, 2004; Alexander \& Crutcher, 1990) and projects to basal ganglia relay structures (including the globus pallidus, the rodent homologue of the external part of the primate globus pallidus) and output structures of the basal ganglia, including the entopeduncular nucleus and the substantia nigra pars reticulata (Hamani et al., 2004; Heimer, Zahm, \& Alheid, 1995), which project on to thalamus and thence to cortex. Lesions of the STN decreased impulsive choice in a task involving choice of a single immediate food pellet or four pellets delivered after a delay (Winstanley, Baunez, Theobald, \& Robbins, 2005), a task in which OFC lesions had the same effect (Winstanley, Theobald, Cardinal, et al., 2004). STN lesions also impaired autoshaping (Winstanley, Baunez, et al., 2005), though this is unlikely to explain the effect to promote choice of LL rewards-not least because AcbC lesions also impair autoshaping (Parkinson, Willoughby, et al., 2000; Cardinal, Parkinson, Lachenal, et al., 2002) but reduce choice of LL rewards (Cardinal et al., 2001), while ACC lesions impair autoshaping (Bussey, Everitt, et al., 1997; Cardinal, Parkinson, et al., 2003; Parkinson, Willoughby, et al., 2000) but do not affect choice between SS/LL rewards (Cardinal et al., 2001), but more simply because there was no explicit CS in this task differentially associated with the two rewards, and approach to which would promote choice of the SS reward. Furthermore, STN lesions tend to increase premature responding, often thought of as an index of motor impulsivity (Baunez et al., 2001; Baunez \& Robbins, 1997). It is not known whether STN lesions affect reward magnitude discrimination or uncertainty discounting.

\subsection{Hippocampus $(H)$}

A role of the hippocampus in learning with delayed reinforcement might be suspected, because there is good evidence that the hippocampus contributes to the representation of context and, as discussed earlier, contextual conditioning is important in learning with delays. Lesions of the hippocampal formation $(\mathrm{H})$ have been shown to impair Pavlovian conditioning to a contextual CS, but not to a discrete CS, in rats (Anagnostaras, Maren, \& Fanselow, 1999; Chen, Kim, Thompson, \& Tonegawa, 1996; Hirsh, 1974; Honey \& Good, 1993; Jarrard, 1993; Kim \& Fanselow, 1992; Kim, Rison, \& Fanselow, 1993; Maren \& Fanselow, 1997; Phillips \& LeDoux, 1992, 1994, 1995; Rudy, Barrientos, \& O'Reilly, 2002; Selden, Everitt, Jarrard, \& Robbins, 1991), at least 
for some processes involving contextual representation (Good, 2002; Good \& Honey, 1991; Holland \& Bouton, 1999). In some cases, discrete CS conditioning has even been enhanced (e.g. Ito, Everitt, and Robbins (2005)). Since context-outcome associations are thought to hinder instrumental learning with delayed reinforcement through contextual competition (Dickinson \& Balleine, 1994; Dickinson et al., 1992), it follows that if $\mathrm{H}$ lesions impair the formation of associations involving the context, such lesions might reduce contextual competition and hence facilitate instrumental conditioning when there is an action-outcome delay.

Indeed, excitotoxic lesions of the $\mathrm{H}$ ameliorate the deleterious effects of response-reinforcer delays on instrumental learning (Cheung \& Cardinal, 2005). Hippocampal-lesioned rats responded slightly less than controls in the absence of delays, but they became better at learning (relative to shams) as the delays increased, in a delay-dependent fashion. This may have been because the lesion hindered the formation of context-outcome associations, promoting response-outcome association instead.

Unexpectedly, in separate experiments $\mathrm{H}$-lesioned rats exhibited impulsive choice, preferring an immediate, small reward to a delayed, larger reward (using a task based on that of Evenden \& Ryan, 1996), even though they preferred the large reward when it was not delayed (Cheung \& Cardinal, 2005). Though a quantitative difference in sensitivity to reinforcer magnitude might explain these results, as discussed above (Ho et al., 1999), H-lesioned rats were able to discriminate the large from the small reinforcer, and such evidence as exists suggests that $\mathrm{H}$-lesioned rats perceive reward magnitude normally (Gilbert \& Kesner, 2002; Kesner \& Williams, 1995). These results also resemble those of Rawlins, Feldon, and Butt (1985), who found that while normal rats preferred immediate certain reward to immediate uncertain reward, and preferred delayed certain reward to immediate uncertain reward, rats with hippocampal or medial septal lesions were less tolerant of the delay (or more tolerant of the uncertainty), preferring immediate uncertain reward to delayed certain reward. Reduced preference for delayed reward in some of these tasks may be explained in terms of altered temporal perception. For example, a lesion that increased the speed of an 'internal clock' (Gibbon, Malapani, Dale, \& Gallistel, 1997) might affect choice prospectively in the task used by Cheung and Cardinal (2005) (i.e. the lesioned subject perceives itself to be at a later time point in the session than it actually is; since the task used a delay for the LL reward that increased across the session, such an effect would hasten the within-session shift towards the SS alternative), or might affect retrospective choice (i.e. the lesioned subject experiences the delay to the large reinforcer as longer than it actually is, causing it to value the reinforcer less than shams). The evidence for the role of the $\mathrm{H}$ in temporal perception is inconclusive: some studies have found that aspirative hippocampal lesions did not affect timing behaviour (Dietrich \& Allen, 1998; Dietrich, Allen, \& Bunnell, 1997; Port, Romano, Steinmetz, Mikhail, \& Patterson, 1986; Rawlins, Winocur, \& Gray, 1983), whereas others have suggested that lesions of the hippocampus or fimbria/fornix speed up an internal clock, or reduce the estimation of time periods when a stimulus being timed is interrupted (Hata \& Okaichi, 1998; Meck, 1988; Meck, Church, \& Olton, 1984; Olton, Meck, \& Church, 1987; Wallenstein, Eichenbaum, \& Hasselmo, 1998). In any case, H-lesioned rats were better at learning with delayed reinforcement but worse at choosing it, suggesting that self-controlled choice and learning with delayed reinforcement tax different psychological processes.

\section{Conclusions}

A number of limbic corticostriatal structures, together with the major forebrain neuromodulatory systems, play a role in learning and choice involving delayed and probabilistic rewards. The contribution of these structures is best understood for delayed reward (Fig. 2), although recent functional imaging and lesion studies have examined the neuroanatomical basis of choice involving uncertain reward.

To summarize, many structures have been implicated in the processing of delayed and/or probabilistic rewards by correlative studies, including studies of abnormalities in disorders of impulsivity such as ADHD, animal single-cell recording studies, and functional imaging studies in normal humans. Impulsive choice (preference for SS over LL rewards) has been induced by lesions of the AcbC, BLA, OFC, and $\mathrm{H}$; self-controlled choice has been induced by lesions of the OFC and STN. Lesions of PrL/IL and ACC do not appear to affect SS/LL reward preference; lesions of the AcbSh do not affect preference between immediate/uncertain and delayed/certain rewards. Studies examining SS/LL preference with a single pair of reinforcers cannot determine whether impulsive or self-controlled choice is due to changes in delay discounting or changes in reinforcer magnitude sensitivity. There is good evidence that changes in reinforcer magnitude sensitivity are minimal following AcbC lesions, and that AcbC damage increases delay discounting. OFC lesions appear both to enhance delay discounting and alter reinforcer magnitude sensitivity. Quantitative determinations of reinforcer magnitude sensitivity following BLA, STN, and H lesions are lacking, though there is some evidence that $\mathrm{H}$ lesions do not affect reward magnitude processing.

Lesions of the AcbC do not only impair choice of delayed rewards, but impair instrumental conditioning specifically when reinforcers are delayed. In contrast, although $\mathrm{H}$ lesions produce impulsive choice in rats, they ameliorate the deleterious effects of delays on instrumental conditioning, possibly by reducing contextual competition.

Other structures may also be involved in delayed reinforcement: in principle, any structure that represents future reinforcers across a delay may contribute to their choice, and exert conditioned reinforcing effects on current behaviour, while any structure that maintains a 'memory trace' of responses across a delay may support the reinforcement of those responses. The ventral striatum and OFC exhibit such activity (Schultz, Apicella, Romo, \& Scarnati, 1995; Schultz et al., 1998, 2000), but so do other structures including the dorsal striatum (e.g. Schultz et al. (1995)), implicated in the reinforcement of stimulus-response habits (Mishkin, Malamut, 
\& Bachevalier, 1984; Packard \& McGaugh, 1996; Robbins \& Everitt, 1992; White, 1997); see Parkinson, Cardinal, et al. (2000).

Neurochemically, DA $\mathrm{D}_{2}$ receptors have been shown to promote self-controlled choice, in that $\mathrm{D}_{2}$ receptor antagonists have the opposite effect. NA blockade appears to affect decision making under uncertainty by reducing loss magnitude discrimination when loss probabilities are high. Forebrain 5-HT also appears to promote self-controlled choice, in that a number of studies have shown impulsive choice following 5-HT depletion or antagonists. However, not all studies have found this effect, the role of 5-HT receptor subtypes and chronic adaptations of this system is complex, and 5-HT interacts with other neuromodulators, including DA. Forebrain 5-HT depletion does not appear to alter reinforcer magnitude discrimination.

Fewer interventional studies have looked at the structures required to choose or learn from uncertain rewards, though $\mathrm{AcbC}$ and OFC lesions both appear to make rats less willing to choose large, uncertain rewards over small, certain rewards. 5-HT does not appear to affect choice between small, certain and large, uncertain rewards. Human imaging studies have implicated a number of regions in decisions involving risk, including parts of the medial prefrontal cortex, the Acb, and the insula. Finally, ACC lesions appear to make rats lazy, in the sense of being less willing to choose large rewards requiring high effort to obtain, when a smaller but low-effort alternative is available.

These studies provide some insight into the pathways through which reward-related information is processed, and suggest underlying neurobiological deficits that may contribute to disorders involving risk taking and impulsive choice. Further considerations apply to drug addiction, since drugs of abuse (including opiates, ethanol, and psychostimulants) can produce chronic adaptations in brain regions including the Acb (see Koob, Sanna, and Bloom (1998)). Human addiction is associated with steep temporal discounting, particularly for the abused drug, and deficits in decision making under uncertainty, and chronic use of psychostimulants has been shown to increase impulsive choice in animal models. One mechanism contributing to addiction may therefore be the ability of drugs of abuse to induce damage or dysfunction in structures that normally promote self-controlled choice, further promoting subsequent impulsive choice and future drug taking. However, we do not yet have a mechanistic description of the way in which delays and probabilities have their effects or are encoded, or the ways in which these various limbic corticostriatal structures interact with each other to enable an animal to choose wisely.

\section{Acknowledgements}

This work was supported by the UK Medical Research Council (MRC) and the Wellcome Trust within the University of Cambridge Behavioural and Clinical Neuroscience Institute. I thank two anonymous referees for their helpful comments.

\section{References}

Aggleton, J. P. (Ed.), (2000). The amygdala: A functional analysis (2nd ed.). New York: Oxford University Press.

Ainslie, G (1975). Specious reward: A behavioral theory of impulsiveness and impulse control. Psychological Bulletin, 82(4), 463-496.

Ainslie, G. (2001). Breakdown of will. Cambridge, UK: Cambridge University Press.

Alexander, G. E., \& Crutcher, M. D. (1990). Functional architecture of basal ganglia circuits: Neural substrates of parallel processing. Trends in Neurosciences, 13, 266-271.

Amiez, C., Joseph, J. P., \& Procyk, E. (2005a). Anterior cingulate errorrelated activity is modulated by predicted reward. European Journal of Neuroscience, 21(12), 3447-3452.

Amiez, C., Joseph, J. P., \& Procyk, E. (2005b). Reward encoding in the monkey anterior cingulate cortex [Advance Access ahead of print; doi:10.1093/cercor/bhj046]. Cerebral Cortex.

Anagnostaras, S. G., Maren, S., \& Fanselow, M. S. (1999). Temporally graded retrograde amnesia of contextual fear after hippocampal damage in rats: Within-subjects examination. Journal of Neuroscience, 19(3), 1106-1114.

Anderson, I. M., Richell, R. A., \& Bradshaw, C. M. (2003). The effect of acute tryptophan depletion on probabilistic choice. Journal of Psychopharmacology, 17(1), 3-7.

APA, (2000). Diagnostic and statistical manual of mental disorders (4th ed.). Washington DC: American Psychiatric Association (text revision (DSMIV-TR)).

Apter, A., Plutchik, R., \& van Praag, H. M. (1993). Anxiety, impulsivity and depressed mood in relation to suicidal and violent behavior. Acta Psychiatrica Scandinavica, 87(1), 1-5.

Aron, A. R., Shohamy, D., Clark, J., Myers, C., Gluck, M. A., \& Poldrack, R. A. (2004). Human midbrain sensitivity to cognitive feedback and uncertainty during classification learning. Journal of Neurophysiology, 92(2), 1144-1152.

Åsberg, M. (1997). Neurotransmitters and suicidal behavior. The evidence from cerebrospinal fluid studies. Annals of the New York Academy of Sciences, 836, 158-181.

Åsberg, M., Träskman, L., \& Thorén, P. (1976). 5-HIAA in the cerebrospinal fluid: A biochemical suicide predictor. Archives of General Psychiatry, 33, 1193-1197.

Aston-Jones, G., Shipley, M. T., \& Grzanna, R. (1995). The locus coeruleus, A5 and A7 noradrenergic cell groups. In G. Paxinos (Ed.), The rat nervous system (pp. 183-213). London: Academic Press.

Bäckman, J., Alling, C., Alsén, M., Regnéll, G., \& Träskman-Bendz, L. (2000). Changes of cerebrospinal fluid monoamine metabolites during long-term antidepressant treatment. European Neuropsychopharmacology, 10(5), 341-349.

Balleine, B., \& Killcross, S. (1994). Effects of ibotenic acid lesions of the nucleus accumbens on instrumental action. Behavioural Brain Research, 65(2), 181-193.

Balleine, B. W., \& Dickinson, A. (1998). Goal-directed instrumental action: Contingency and incentive learning and their cortical substrates. Neuropharmacology, 37(4-5), 407-419.

Barto, A. G. (1995). Adaptive critics and the basal ganglia. In J. C. Houk, J. L. Davis, \& D. G. Beiser (Eds.), Models of information processing in the basal ganglia (pp. 215-232). Cambridge, Massachusetts: MIT Press.

Bassareo, V., \& Di Chiara, G. (1999). Differential responsiveness of dopamine transmission to food-stimuli in nucleus accumbens shell/core compartments. Neuroscience, 89(3), 637-641.

Basso, A. M., \& Kelley, A. E. (1999). Feeding induced by GABA(A) receptor stimulation within the nucleus accumbens shell: Regional mapping and characterization of macronutrient and taste preference. Behavioral Neuroscience, 113(2), 324-336.

Baunez, C., Humby, T., Eagle, D. M., Ryan, L. J., Dunnett, S. B., \& Robbins, T. W. (2001). Effects of STN lesions on simple vs choice reaction time tasks in the rat: Preserved motor readiness, but impaired response selection. European Journal of Neuroscience, 13(8), 1609-1616.

Baunez, C., \& Robbins, T. W. (1997). Bilateral lesions of the subthalamic nucleus induce multiple deficits in an attentional task in rats. European Journal of Neuroscience, 9(10), 2086-2099. 
Bechara, A., Damasio, A. R., Damasio, H., \& Anderson, S. W. (1994). Insensitivity to future consequences following damage to human prefrontal cortex. Cognition, 50(1-3), 7-15.

Bechara, A., Damasio, H., Damasio, A. R., \& Lee, G. P. (1999). Different contributions of the human amygdala and ventromedial prefrontal cortex to decision-making. Journal of Neuroscience, 19(13), 5473-5481.

Bechara, A., Damasio, H., Tranel, D., \& Damasio, A. R. (1997). Deciding advantageously before knowing the advantageous strategy. Science, 275(5304), 1293-1295.

Bechara, A., Tranel, D., Damasio, H., \& Damasio, A. R. (1996). Failure to respond autonomically to anticipated future outcomes following damage to prefrontal cortex. Cerebral Cortex, 6(2), 215-225.

Berendse, H. W., \& Groenewegen, H. J. (1991). The connections of the medial part of the subthalamic nucleus in the rat: Evidence for a parallel organization. In G. Bernardi, M. B. Carpenter, G. DiChiara, M. Morelli, \& P. Stanzione (Eds.), The basal ganglia III (pp. 89-98). New York: Plenum.

Berridge, K. C. (2000). Measuring hedonic impact in animals and infants: Microstructure of affective taste reactivity patterns. Neuroscience and Biobehavioral Reviews, 24(2), 173-198.

Bickel, W. K., Odum, A. L., \& Madden, G. J. (1999). Impulsivity and cigarette smoking: Delay discounting in current, never, and ex-smokers. Psychopharmacology, 146(4), 447-454.

Biggio, G., Fadda, F., Fanni, P., Tagliamonte, A., \& Gessa, G. (1974). Rapid depletion of serum tryptophan, brain tryptophan, serotonin and 5-hydroxyindoleacetic acid by a trytophan-free diet. Life Sciences, 14, 1321-1329.

Bizot, J., Le Bihan, C., Puech, A. J., Hamon, M., \& Thiébot, M. (1999). Serotonin and tolerance to delay of reward in rats. Psychopharmacology, 146(4), 400-412.

Bjork, J. M., Knutson, B., Fong, G. W., Caggiano, D. M., Bennett, S. M., \& Hommer, D. W. (2004). Incentive-elicited brain activation in adolescents: Similarities and differences from young adults. Journal of Neuroscience, 24(8), 1793-1802.

Bradley, C. (1937). The behavior of children receiving Benzedrine. American Journal of Psychiatry, 94, 577-585.

Bradshaw, C. M., \& Szabadi, E. (1992). Choice between delayed reinforcers in a discrete-trials schedule - the effect of deprivation level. Quarterly Journal of Experimental Psychology, Section B-Comparative and Physiological Psychology, 44B(1), 1-16.

Breiter, H. C., Aharon, I., Kahneman, D., Dale, A., \& Shizgal, P. (2001). Functional imaging of neural responses to expectancy and experience of monetary gains and losses. Neuron, 30(2), 619-639.

Brog, J. S., Salyapongse, A., Deutch, A. Y., \& Zahm, D. S. (1993). The patterns of afferent innervation of the core and shell in the "accumbens" part of the rat ventral striatum: Immunohistochemical detection of retrogradely transported fluoro-gold. Journal of Comparative Neurology, 338(2), 255-278.

Brown, G. L., \& Linnoila, M. (1990). CSF serotonin metabolite (5HIAA) studies in depression, impulsivity and violence. Journal of Clinical Psychiatry, 51(Suppl. 4), 31-41.

Brown, V. J., \& Bowman, E. M. (1995). Discriminative cues indicating reward magnitude continue to determine reaction time of rats following lesions of the nucleus accumbens. European Journal of Neuroscience, 7(12), 2479-2485.

Burk, J. A., \& Mair, R. G. (2001). Effects of dorsal and ventral striatal lesions on delayed matching trained with retractable levers. Behavioural Brain Research, 122(1), 67-78.

Bush, G., Frazier, J. A., Rauch, S. L., Seidman, L. J., Whalen, P. J., Jenike, M. A., et al. (1999). Anterior cingulate cortex dysfunction in attentiondeficit/hyperactivity disorder revealed by fMRI and the Counting Stroop. Biological Psychiatry, 45(12), 1542-1552.

Bussey, T. J., Everitt, B. J., \& Robbins, T. W. (1997). Dissociable effects of cingulate and medial frontal cortex lesions on stimulus-reward learning using a novel Pavlovian autoshaping procedure for the rat: Implications for the neurobiology of emotion. Behavioral Neuroscience, 111(5), 908-919.

Bussey, T. J., Muir, J. L., Everitt, B. J., \& Robbins, T. W. (1997). Triple dissociation of anterior cingulate, posterior cingulate, and medial frontal cortices on visual discrimination tasks using a touchscreen testing procedure for the rat. Behavioral Neuroscience, 111(5), 920-936.
Cador, M., Taylor, J. R., \& Robbins, T. W. (1991). Potentiation of the effects of reward-related stimuli by dopaminergic-dependent mechanisms in the nucleus accumbens. Psychopharmacology, 104(3), 377-385.

Cardinal, R. N., \& Cheung, T. H. C. (2005). Nucleus accumbens core lesions retard instrumental learning and performance with delayed reinforcement in the rat. BMC Neuroscience, 6, 9 .

Cardinal, R. N., \& Howes, N. J. (2005). Effects of lesions of the nucleus accumbens core on choice between small certain rewards and large uncertain rewards in rats. BMC Neuroscience, 6(1), 37.

Cardinal, R. N., Parkinson, J. A., Djafari Marbini, H., Toner, A. J., Bussey, T. J., Robbins, T. W., et al. (2003). Role of the anterior cingulate cortex in the control over behaviour by Pavlovian conditioned stimuli in rats. Behavioral Neuroscience, 117, 566-587.

Cardinal, R. N., Parkinson, J. A., Hall, J., \& Everitt, B. J. (2002). Emotion and motivation: The role of the amygdala, ventral striatum, and prefrontal cortex. Neuroscience and Biobehavioral Reviews, 26, 321-352.

Cardinal, R. N., Parkinson, J. A., Lachenal, G., Halkerston, K. M., Rudarakanchana, N., Hall, J., et al. (2002). Effects of selective excitotoxic lesions of the nucleus accumbens core, anterior cingulate cortex, and central nucleus of the amygdala on autoshaping performance in rats. Behavioral Neuroscience, 116, 553-567.

Cardinal, R. N., Pennicott, D. R., Sugathapala, C. L., Robbins, T. W., \& Everitt, B. J. (2001). Impulsive choice induced in rats by lesions of the nucleus accumbens core. Science, 292, 2499-2501.

Cardinal, R. N., Robbins, T. W., \& Everitt, B. J. (2000). The effects of d-amphetamine, chlordiazepoxide, alpha-flupenthixol and behavioural manipulations on choice of signalled and unsignalled delayed reinforcement in rats. Psychopharmacology, 152, 362-375.

Cardinal, R. N., Robbins, T. W., \& Everitt, B. J. (2003). Choosing delayed rewards: Perspectives from learning theory, neurochemistry, and neuroanatomy. In N. Heather, \& R. E. Vuchinich (Eds.), Choice, behavioral economics and addiction (pp. 183-213). Oxford: Elsevier (pp. 217-218).

Cardinal, R. N., Winstanley, C. A., Robbins, T. W., \& Everitt, B. J. (2004). Limbic corticostriatal systems and delayed reinforcement. Annals of the New York Academy of Sciences, 1021, 33-50.

Carey, M. P., Diewald, L. M., Esposito, F. J., Pellicano, M. P., Carnevale, U. A. G., Sergeant, J. A., et al. (1998). Differential distribution, affinity and plasticity of dopamine D-1 and D-2 receptors in the target sites of the mesolimbic system in an animal model of ADHD. Behavioural Brain Research, 94(1), 173-185.

Carpenter, L. L., Anderson, G. M., Pelton, G. H., Gudin, J. A., Kirwin, P. D., Price, L. H., et al. (1998). Tryptophan depletion during continuous CSF sampling in healthy human subjects. Neuropsychopharmacology, 19(1), 26-35.

Caspi, A., Sugden, K., Moffitt, T. E., Taylor, A., Craig, I. W., Harrington, H., et al. (2003). Influence of life stress on depression: Moderation by a polymorphism in the 5-HTT gene. Science, 301(5631), 386-389.

Catania, A. C. (1970). Reinforcement schedules and psychophysical judgment: A study of some temporal properties of behavior. In W. N. Schoenfeld (Ed.), The theory of reinforcement schedules (pp. 1-42). New York: Appleton-Century-Crofts.

Charrier, D., \& Thiébot, M. H. (1996). Effects of psychotropic drugs on rat responding in an operant paradigm involving choice between delayed reinforcers. Pharmacology, Biochemistry and Behavior, 54(1), 149-157.

Chen, C., Kim, J. J., Thompson, R. F., \& Tonegawa, S. (1996). Hippocampal lesions impair contextual fear conditioning in two strains of mice. Behavioral Neuroscience, 110(5), 1177-1180.

Cheung, T. H., \& Cardinal, R. N. (2005). Hippocampal lesions facilitate instrumental learning with delayed reinforcement but induce impulsive choice in rats. BMC Neuroscience, 6(1), 36.

Christakou, A., Robbins, T. W., \& Everitt, B. J. (2004). Prefrontal cortical-ventral striatal interactions involved in affective modulation of attentional performance: Implications for corticostriatal circuit function. Journal of Neuroscience, 24(4), 773-780.

Clark, L., Manes, F., Antoun, N., Sahakian, B. J., \& Robbins, T. W. (2003). The contributions of lesion laterality and lesion volume to decision-making impairment following frontal lobe damage. Neuropsychologia, 41(11), 1474-1483. 
Clark, L., Roiser, J. P., Cools, R., Rubinsztein, D. C., Sahakian, B. J., \& Robbins, T. W. (2005). Stop signal response inhibition is not modulated by tryptophan depletion or the serotonin transporter polymorphism in healthy volunteers: Implications for the 5-HT theory of impulsivity. Psychopharmacology, 182(4), 570-578.

Clemens, J. A., Bennett, D. R., \& Fuller, R. W. (1980). The effect of a tryptophan-free diet on prolactin and corticosterone release by serotonergic stimuli. Hormone and Metabolic Research, 12(1), 35-38.

Coccaro, E. F., \& Siever, L. J. (1995). The neuropsychopharmacology of personality disorders. In F. E. Bloom, \& D. J. Kupfer (Eds.), Psychopharmacology: The fourth generation of progress: vol. 1567-1579. New York: American College of Neuropsychopharmacology/Raven Press, http://www.acnp.org/content-32.html.

Coffey, S. F., Gudleski, G. D., Saladin, M. E., \& Brady, K. T. (2003). Impulsivity and rapid discounting of delayed hypothetical rewards in cocaine-dependent individuals. Experimental and Clinical Psychopharmacology, 11(1), 18-25.

Cole, B. J., \& Robbins, T. W. (1989). Effects of 6-hydroxydopamine lesions of the nucleus accumbens septi on performance of a 5-choice serial reaction time task in rats: Implications for theories of selective attention and arousal. Behavioural Brain Research, 33(2), 165-179.

Coleman-Mesches, K., Salinas, J. A., \& McGaugh, J. L. (1996). Unilateral amygdala inactivation after training attenuates memory for reduced reward. Behavioural Brain Research, 77(1-2), 175-180.

Cools, R., Blackwell, A., Clark, L., Menzies, L., Cox, S., \& Robbins, T. W. (2005). Tryptophan depletion disrupts the motivational guidance of goaldirected behavior as a function of trait impulsivity. Neuropsychopharmacology, 30(7), 1362-1373.

Cooper, S. J., Kelly, C. B., \& King, D. J. (1992). 5-Hydroxyindoleacetic acid in cerebrospinal fluid and prediction of suicidal behaviour in schizophrenia. Lancet, 340(8825), 940-941.

Corruble, E., Benyamina, A., Bayle, F., Falissard, B., \& Hardy, P. (2003). Understanding impulsivity in severe depression? A psychometrical contribution. Progress in Neuro-Psychopharmacology and Biological Psychiatry, 27(5), 829-833.

Cousins, M. S., Atherton, A., Turner, L., \& Salamone, J. D. (1996). Nucleus accumbens dopamine depletions alter relative response allocation in a $\mathrm{T}$ maze cost/benefit task. Behavioural Brain Research, 74(1-2), 189-197.

Crean, J., Richards, J. B., \& de Wit, H. (2002). Effect of tryptophan depletion on impulsive behavior in men with or without a family history of alcoholism. Behavioural Brain Research, 136(2), 349-357.

Cremniter, D., Jamain, S., Kollenbach, K., Alvarez, J. C., Lecrubier, Y., Gilton, A., et al. (1999). CSF 5-HIAA levels are lower in impulsive as compared to nonimpulsive violent suicide attempters and control subjects. Biological Psychiatry, 45(12), 1572-1579.

Cromwell, H. C., \& Schultz, W. (2003). Effects of expectations for different reward magnitudes on neuronal activity in primate striatum. Journal of Neurophysiology, 89(5), 2823-2838.

Dalley, J. W., Theobald, D. E., Eagle, D. M., Passetti, F., \& Robbins, T. W. (2002). Deficits in impulse control associated with tonically-elevated serotonergic function in rat prefrontal cortex. Neuropsychopharmacology, 26(6), 716-728.

Daruna, J. H., \& Barnes, P. A. (1993). A neurodevelopmental view of impulsivity. In W. G. McCown, J. L. Johnson, \& M. B. Shure (Eds.), The impulsive client: Theory, research and treatment. Washington, DC: American Psychological Association.

Daw, N. D., Niv, Y., \& Dayan, P. (2005a). Actions, policies, values, and the basal ganglia. In E. Bezard (Ed.), Recent breakthroughs in basal ganglia research. New York: Nova Science Publishers.

Daw, N. D., Niv, Y., \& Dayan, P. (2005b). Uncertainty-based competition between prefrontal and dorsolateral striatal systems for behavioral control. Nature Neuroscience, 8(12), 1704-1711.

Daw, N. D., \& Touretzky, D. S. (2002). Long-term reward prediction in TD models of the dopamine system. Neural Computation, 14(11), 2567-2583.

de Borchgrave, R., Rawlins, J. N., Dickinson, A., \& Balleine, B. W. (2002). Effects of cytotoxic nucleus accumbens lesions on instrumental conditioning in rats. Experimental Brain Research, 144(1), 50-68. de Villiers, A. S., Russell, V. A., Sagvolden, T., Searson, A., Jaffer, A., \& Taljaard, J. J. (1995). Alpha 2-adrenoceptor mediated inhibition of $[3 \mathrm{H}]$ dopamine release from nucleus accumbens slices and monoamine levels in a rat model for attention-deficit hyperactivity disorder. Neurochemical Research, 20(4), 427-433.

de Wit, H., Enggasser, J. L., \& Richards, J. B. (2002). Acute administration of d-amphetamine decreases impulsivity in healthy volunteers. Neuropsychopharmacology, 27(5), 813-825.

Deakin, J., Aitken, M., Robbins, T., \& Sahakian, B. J. (2004). Risk taking during decision-making in normal volunteers changes with age. Journal of the International Neuropsychological Society, 10(4), 590-598.

Delgado, P. L., Charney, D. S., Price, L. H., Aghajanian, G. K., Landis, H., \& Heninger, G. R. (1990). Serotonin function and the mechanism of antidepressant action. Reversal of antidepressant-induced remission by rapid depletion of plasma tryptophan. Archives of General Psychiatry, 47(5), 411-418.

Delgado, P. L., Charney, D. S., Price, L. H., Landis, H., \& Heninger, G. R. (1989). Neuroendocrine and behavioral effects of dietary tryptophan restriction in healthy subjects. Life Sciences, 45(24), 2323-2332.

Dhaenen, H. (2001). Imaging the serotonergic system in depression. European Archives of Psychiatry and Clinical Neuroscience, 251(Suppl. 2), II76-II80.

Dickinson, A. (1980). Contemporary animal learning theory. Cambridge: Cambridge University Press.

Dickinson, A. (1994). Instrumental conditioning. In N. J. Mackintosh (Ed.), Animal learning and cognition (pp. 45-79). San Diego: Academic Press.

Dickinson, A., \& Balleine, B. (1994). Motivational control of goal-directed action. Animal Learning \& Behavior, 22(1), 1-18.

Dickinson, A., Watt, A., \& Griffiths, W. J. H. (1992). Free-operant acquisition with delayed reinforcement. Quarterly Journal of Experimental Psychology, Section B-Comparative and Physiological Psychology, 45(3), 241-258.

Dietrich, A., \& Allen, J. D. (1998). Functional dissociation of the prefrontal cortex and the hippocampus in timing behavior. Behavioral Neuroscience, 112(5), 1043-1047.

Dietrich, A., Allen, J. D., \& Bunnell, B. N. (1997). Is the hippocampus involved in temporal discrimination and the memory of short intervals? International Journal of Neuroscience, 90(3-4), 255-269.

Dunnett, S. B. (1990). Role of prefrontal cortex and striatal output systems in short-term memory deficits associated with ageing, basal forebrain lesions, and cholinergic-rich grafts. Canadian Journal of Psychology, 44(2), 210-232.

Eagle, D. M., \& Robbins, T. W. (2003). Lesions of the medial prefrontal cortex or nucleus accumbens core do not impair inhibitory control in rats performing a stop-signal reaction time task. Behavioural Brain Research, 146(1-2), 131-144.

Ernst, M., Nelson, E. E., McClure, E. B., Monk, C. S., Munson, S., Eshel, N., et al. (2004). Choice selection and reward anticipation: An fMRI study. Neuropsychologia, 42(12), 1585-1597.

Ernst, M., Zametkin, A. J., Matochik, J. A., Jons, P. H., \& Cohen, R. M. (1998). DOPA decarboxylase activity in attention deficit hyperactivity disorder adults. A [fluorine-18]fluorodopa positron emission tomographic study. Journal of Neuroscience, 18(15), 5901-5907.

Ersche, K. D., Roiser, J. P., Clark, L., London, M., Robbins, T. W., \& Sahakian, B. J. (2005). Punishment induces risky decision-making in methadonemaintained opiate users but not in heroin users or healthy volunteers. Neuropsychopharmacology, 30(11), 2115-2124.

Evenden, J. L. 1998. Serotonergic and steroidal influences on impulsive behaviour in rats. In: Comprehensive summaries of Uppsala dissertations from the faculty of medicine, vol. 764.

Evenden, J. L. (1999a). Impulsivity: A discussion of clinical and experimental findings. Journal of Psychopharmacology, 13, 180-192.

Evenden, J. L. (1999b). Varieties of impulsivity. Psychopharmacology, 146(4), $348-361$.

Evenden, J. L., \& Meyerson, B. (1999). The behavior of spontaneously hypertensive and Wistar Kyoto rats under a paced fixed consecutive number schedule of reinforcement. Pharmacology, Biochemistry and Behavior, 63(1), 71-82. 
Evenden, J. L., \& Ryan, C. N. (1996). The pharmacology of impulsive behaviour in rats: The effects of drugs on response choice with varying delays of reinforcement. Psychopharmacology, 128(2), 161-170.

Evenden, J. L., \& Ryan, C. N. (1999). The pharmacology of impulsive behaviour in rats VI: The effects of ethanol and selective serotonergic drugs on response choice with varying delays of reinforcement. Psychopharmacology, 146(4), 413-421.

Everitt, B. J., Parkinson, J. A., Olmstead, M. C., Arroyo, M., Robledo, P., \& Robbins, T. W. (1999). Associative processes in addiction and reward: The role of amygdala-ventral striatal subsystems. Annals of the New York Academy of Sciences, 877, 412-438.

Eysenck, S. G. B. (1993). The I7: Development of a measure of impulsivity and its relationship to the superfactors of personality. In W. G. McCown, J. L. Johnson, \& M. B. Shure (Eds.), The impulsive client: Theory, research and treatment. Washington DC: American Psychological Association.

Fallon, J. H., \& Loughlin, S. E. (1995). Substantia nigra. In G. Paxinos (Ed.), The rat nervous system (pp. 215-237). London: Academic Press.

Feldman, R. S., Meyer, J. S., \& Quenzer, L. F. (1997). Principles of neuropsychopharmacology. Sunderland, Massachusetts: Sinauer.

Fellows, L. K., \& Farah, M. J. (2005). Different underlying impairments in decision-making following ventromedial and dorsolateral frontal lobe damage in humans. Cerebral Cortex, 15(1), 58-63.

Fiorillo, C. D., Tobler, P. N., \& Schultz, W. (2003). Discrete coding of reward probability and uncertainty by dopamine neurons. Science, 299(5614), 1898-1902.

Fiorillo, C. D., Tobler, P. N., \& Schultz, W. (2005). Evidence that the delayperiod activity of dopamine neurons corresponds to reward uncertainty rather than backpropagating TD errors. Behavioral and Brain Functions, $1(1), 7$.

Fone, K. C., \& Nutt, D. J. (2005). Stimulants: Use and abuse in the treatment of attention deficit hyperactivity disorder. Current Opinion in Pharmacology, $5(1), 87-93$.

Gallistel, C. R. (1994). Space and time. In N. J. Mackintosh (Ed.), Animal learning and cognition (pp. 221-253). San Diego: Academic Press.

George, S., Rogers, R. D., \& Duka, T. (2005). The acute effect of alcohol on decision making in social drinkers. Psychopharmacology, 182(1), 160-169.

Gibbon, J., Malapani, C., Dale, C. L., \& Gallistel, C. (1997). Toward a neurobiology of temporal cognition: Advances and challenges. Current Opinion in Neurobiology, 7(2), 170-184.

Giertler, C., Bohn, I., \& Hauber, W. (2003). The rat nucleus accumbens is involved in guiding of instrumental responses by stimuli predicting reward magnitude. European Journal of Neuroscience, 18(7), 1993-1996.

Giertler, C., Bohn, I., \& Hauber, W. (2004). Transient inactivation of the rat nucleus accumbens does not impair guidance of instrumental behaviour by stimuli predicting reward magnitude. Behavioural Pharmacology, 15(1), $55-63$.

Gilbert, P. E., \& Kesner, R. P. (2002). The amygdala but not the hippocampus is involved in pattern separation based on reward value. Neurobiology of Learning and Memory, 77(3), 338-353.

Gjelsvik, O. (2003). Reason and addiction. In N. Heather, \& R. E. Vuchinich (Eds.), Choice, behavioral economics and addiction (pp. 219-238). Oxford: Elsevier (pp. 245-247).

Good, M. (2002). Spatial memory and hippocampal function: Where are we now? Psicológica, 23, 109-138.

Good, M., \& Honey, R. C. (1991). Conditioning and contextual retrieval in hippocampal rats. Behavioral Neuroscience, 105(4), 499-509.

Grace, R. C. (1996). Choice between fixed and variable delays to reinforcement in the adjusting-delay procedure and concurrent chains. Journal of Experimental Psychology: Animal Behavior Processes, 22(3), 362-383.

Green, L., Fisher, E. B., Perlow, S., \& Sherman, L. (1981). Preference reversal and self control: Choice as a function of reward amount and delay. Behaviour Analysis Letters, 1, 43-51.

Green, L., \& Myerson, J. (1996). Exponential versus hyperbolic discounting of delayed outcomes: Risk and waiting time. American Zoologist, 36, 496-505.

Green, L., \& Myerson, J. (2004). A discounting framework for choice with delayed and probabilistic rewards. Psychological Bulletin, 130(5), 769-792.
Green, L., Myerson, J., \& Ostaszewski, P. (1999). Amount of reward has opposite effects on the discounting of delayed and probabilistic outcomes. Journal of Experimental Psychology. Learning, Memory, and Cognition, 25(2), 418-427.

Grice, G. R. (1948). The relation of secondary reinforcement to delayed reward in visual discrimination learning. Journal of Experimental Psychology, $38(1), 1-16$

Grindley, G. C. (1932). The formation of a simple habit in guinea pigs. British Journal of Psychology, 23, 127-147.

Guthrie, E. R. (1935). The psychology of learning. New York: Harper.

Hall, G. (1994). Pavlovian conditioning: Laws of association. In N. J. Mackintosh (Ed.), Animal learning and cognition (pp. 15-43). San Diego: Academic Press.

Hall, J., Parkinson, J. A., Connor, T. M., Dickinson, A., \& Everitt, B. J. (2001). Involvement of the central nucleus of the amygdala and nucleus accumbens core in mediating Pavlovian influences on instrumental behaviour. European Journal of Neuroscience, 13(10), 1984-1992.

Halliday, G., Harding, A., \& Paxinos, G. (1995). Serotonin and tachykinin systems. In G. Paxinos (Ed.), The rat nervous system (pp. 929-974). London: Academic Press.

Hamani, C., Saint-Cyr, J. A., Fraser, J., Kaplitt, M., \& Lozano, A. M. (2004). The subthalamic nucleus in the context of movement disorders. Brain, 127(Pt 1), 4-20.

Harker, G. S. (1956). Delay of reward and performance of an instrumental response. Journal of Experimental Psychology, 51, 303-310.

Hata, T., \& Okaichi, H. (1998). Effects of fimbria-fornix lesion on the temporal discrimination revealed by peak interval procedure in rats. Shinrigaku Kenkyu (Japanese Journal of Psychology), 69(4), 304-309.

Hauber, W., Bohn, I., \& Giertler, C. (2000). NMDA, but not dopamine $\mathrm{D}(2)$, receptors in the rat nucleus accumbens are involved in guidance of instrumental behavior by stimuli predicting reward magnitude. Journal of Neuroscience, 20(16), 6282-6288.

Heimer, L., Zahm, D. S., \& Alheid, G. F. (1995). Basal ganglia. In G. Paxinos (Ed.), The rat nervous system (pp. 579-628). London: Academic Press.

Heyman, G. M. (1996). Resolving the contradictions of addiction. Behavioral and Brain Sciences, 19(4), 561-610.

Hikosaka, K., \& Watanabe, M. (2000). Delay activity of orbital and lateral prefrontal neurons of the monkey varying with different rewards. Cerebral Cortex, 10(3), 263-271.

Hill, R. T. (1970). Facilitation of conditioned reinforcement as a mechanism of psychomotor stimulation. In E. Costa, \& S. Garattini (Eds.), International symposium on amphetamines and related compounds (pp. 781-795). New York: Raven Press.

Hirsh, R. (1974). The hippocampus and contextual retrieval of information from memory: A theory. Behavioral Biology, 12(4), 421-444.

Ho, M. Y., Mobini, S., Chiang, T. J., Bradshaw, C. M., \& Szabadi, E. (1999). Theory and method in the quantitative analysis of "impulsive choice" behaviour: Implications for psychopharmacology. Psychopharmacology, 146(4), 362-372.

Holland, P. C., \& Bouton, M. E. (1999). Hippocampus and context in classical conditioning. Current Opinion in Neurobiology, 9, 195-202.

Holt, D. D., Green, L., \& Myerson, J. (2003). Is discounting impulsive? Evidence from temporal and probability discounting in gambling and nongambling college students. Behavioural Processes, 64(3), 355-367.

Holyoak, K. J., \& Spellman, B. A. (1993). Thinking. Annual Review of Psychology, 44, 265-315.

Honey, R. C., \& Good, M. (1993). Selective hippocampal lesions abolish the contextual specificity of latent inhibition and conditioning. Behavioral Neuroscience, 107(1), 23-33.

Houk, J. C., Adams, J. L., \& Barto, A. G. (1995). A model of how the basal ganglia generate and use neural signals that predict reinforcement. In J. C. Houk, J. L. Davis, \& D. G. Beiser (Eds.), Models of information processing in the basal ganglia (pp. 249-270). Cambridge, Massachusetts, London: MIT Press.

Hull, C. L. (1932). The goal gradient hypothesis and maze learning. Psychological Review, 39, 25-43.

Hull, C. L. (1943). Principles of behavior. New York: Appleton-CenturyCrofts. 
Ikemoto, S., \& Panksepp, J. (1999). The role of nucleus accumbens dopamine in motivated behavior: A unifying interpretation with special reference to reward-seeking. Brain Research Reviews, 31(1), 6-41.

Ito, M. (1985). Choice and amount of reinforcement in rats. Learning \& Motivation, 16, 95-108.

Ito, R., Dalley, J. W., Howes, S. R., Robbins, T. W., \& Everitt, B. J. (2000). Dissociation in conditioned dopamine release in the nucleus accumbens core and shell in response to cocaine cues and during cocaine-seeking behavior in rats. Journal of Neuroscience, 20(19), 7489-7495.

Ito, R., Everitt, B. J., \& Robbins, T. W. (2005). The hippocampus and appetitive Pavlovian conditioning: Effects of excitotoxic hippocampal lesions on conditioned locomotor activity and autoshaping. Hippocampus, 15(6), 713-721.

Izawa, E., Aoki, N., \& Matsushima, T. (2005). Neural correlates of the proximity and quantity of anticipated food rewards in the ventral striatum of domestic chicks. European Journal of Neuroscience, 22(6), 1502-1512.

Izawa, E., Zachar, G., Yanagihara, S., \& Matsushima, T. (2003). Localized lesion of caudal part of lobus parolfactorius caused impulsive choice in the domestic chick: Evolutionarily conserved function of ventral striatum. Journal of Neuroscience, 23(5), 1894-1902.

Izquierdo, A., \& Murray, E. A. (2005). Opposing effects of amygdala and orbital prefrontal cortex lesions on the extinction of instrumental responding in macaque monkeys. European Journal of Neuroscience, 22(9), 2341-2346.

Jarrard, L. E. (1993). On the role of the hippocampus in learning and memory in the rat. Behavioral and Neural Biology, 60(1), 9-26.

Johansen, E. B., Aase, H., Meyer, A., \& Sagvolden, T. (2002). Attentiondeficit/hyperactivity disorder (ADHD) behaviour explained by dysfunctioning reinforcement and extinction processes. Behavioural Brain Research, $130(1-2), 37-45$.

Jongen-Relo, A. L., Kaufmann, S., \& Feldon, J. (2003). A differential involvement of the shell and core subterritories of the nucleus accumbens of rats in memory processes. Behavioral Neuroscience, 117(1), 150-168.

Kacelnik, A. (1997a). Normative and descriptive models of decision making: Time discounting and risk sensitivity. In Characterizing human psychological adaptations (Ciba foundation symposium 208) (pp. 51-70). Chichester: Wiley.

Kacelnik, A. (1997b). Normative and descriptive models of decision making: Time discounting and risk sensitivity. In CIBA foundation symposium 208 (pp. 51-67). discussion 67-70.

Kelley, A. E. (1999). Neural integrative activities of nucleus accumbens subregions in relation to learning and motivation. Psychobiology, 27(2), 198-213.

Kelley, A. E., \& Berridge, K. C. (2002). The neuroscience of natural rewards: Relevance to addictive drugs. Journal of Neuroscience, 22(9), 3306-3311.

Kelley, A. E., \& Swanson, C. J. (1997). Feeding induced by blockade of AMPA and kainate receptors within the ventral striatum: A microinfusion mapping study. Behavioural Brain Research, 89(1-2), 107-113.

Kesner, R. P., \& Williams, J. M. (1995). Memory for magnitude of reinforcement: Dissociation between the amygdala and hippocampus. Neurobiology of Learning and Memory, 64(3), 237-244.

Kheramin, S., Body, S., Herrera, F. M., Bradshaw, C. M., Szabadi, E., Deakin, J. F., et al. (2005). The effect of orbital prefrontal cortex lesions on performance on a progressive ratio schedule: Implications for models of inter-temporal choice. Behavioural Brain Research, 156(1), 145-152.

Kheramin, S., Body, S., Ho, M., Velazquez-Martinez, D. N., Bradshaw, C. M., Szabadi, E., et al. (2003). Role of the orbital prefrontal cortex in choice between delayed and uncertain reinforcers: A quantitative analysis. Behavioural Processes, 64(3), 239-250.

Kheramin, S., Body, S., Ho, M. Y., Velazquez-Martinez, D. N., Bradshaw, C. M., Szabadi, E., et al. (2004). Effects of orbital prefrontal cortex dopamine depletion on inter-temporal choice: A quantitative analysis. Psychopharmacology, 175(2), 206-214.

Kheramin, S., Body, S., Mobini, S., Ho, M. Y., Velazquez-Martinez, D. N., Bradshaw, C. M., et al. (2002). Effects of quinolinic acid-induced lesions of the orbital prefrontal cortex on inter-temporal choice: A quantitative analysis. Psychopharmacology, 165(1), 9-17.
Kieres, A. K., Hausknecht, K. A., Farrar, A. M., Acheson, A., de Wit, H., \& Richards, J. B. (2004). Effects of morphine and naltrexone on impulsive decision making in rats. Psychopharmacology, 173(1-2), 167-174.

Killeen, P. R. (1972). The matching law. Journal of the Experimental Analysis of Behavior, 17, 489-495.

Killeen, P. R., \& Fetterman, J. G. (1988). A behavioral theory of timing. Psychological Review, 95(2), 274-295.

Kim, J. J., \& Fanselow, M. S. (1992). Modality-specific retrograde amnesia of fear. Science, 256(5057), 675-677.

Kim, J. J., Rison, R. A., \& Fanselow, M. S. (1993). Effects of amygdala, hippocampus, and periaqueductal gray lesions on short- and long-term contextual fear. Behavioral Neuroscience, 107(6), 1093-1098.

Kirby, K. N., \& Petry, N. M. (2004). Heroin and cocaine abusers have higher discount rates for delayed rewards than alcoholics or non-drug-using controls. Addiction, 99(4), 461-471.

Kirby, K. N., Petry, N. M., \& Bickel, W. K. (1999). Heroin addicts have higher discount rates for delayed rewards than non-drug-using controls. Journal of Experimental Psychology: General, 128(1), 78-87.

Knutson, B., Adams, C. M., Fong, G. W., \& Hommer, D. (2001). Anticipation of increasing monetary reward selectively recruits nucleus accumbens. Journal of Neuroscience, 21(16), RC159.

Knutson, B., Taylor, J., Kaufman, M., Peterson, R., \& Glover, G. (2005). Distributed neural representation of expected value. Journal of Neuroscience, 25(19), 4806-4812.

Koob, G. F., Sanna, P. P., \& Bloom, F. E. (1998). Neuroscience of addiction. Neuron, 21(3), 467-476.

Kuhnen, C. M., \& Knutson, B. (2005). The neural basis of financial risk taking. Neuron, 47(5), 763-770.

Kuntsi, J., Oosterlaan, J., \& Stevenson, J. (2001). Psychological mechanisms in hyperactivity: I. Response inhibition deficit, working memory impairment, delay aversion, or something else? Journal of Child Psychology and Psychiatry and Allied Disciplines, 42(2), 199-210.

Lagorio, C. H., \& Madden, G. J. (2005). Delay discounting of real and hypothetical rewards III: Steady-state assessments, forced-choice trials, and all real rewards. Behavioural Processes, 69(2), 173-187.

Lane, S. D., Cherek, D. R., Pietras, C. J., \& Tcheremissine, O. V. (2004). Alcohol effects on human risk taking. Psychopharmacology, 172(1), 68-77.

Lattal, K. A. (1987). Considerations in the experimental analysis of reinforcement delay. In M. L. Commons, J. E. Mazur, J. A. Nevin, \& H. Rachlin (Eds.), Quantitative analyses of behavior: V. The effect of delay and of intervening events on reinforcement value (pp. 107-123). Hillsdale, New Jersey: Lawrence Erlbaum.

Lattal, K. A., \& Gleeson, S. (1990). Response acquisition with delayed reinforcement. Journal of Experimental Psychology: Animal Behavior Processes, 16(1), 27-39.

Leland, D. S., \& Paulus, M. P. (2005). Increased risk-taking decision-making but not altered response to punishment in stimulant-using young adults. Drug and Alcohol Dependence, 78(1), 83-90.

Levita, L., Dalley, J. W., \& Robbins, T. W. (2002). Disruption of Pavlovian contextual conditioning by excitotoxic lesions of the nucleus accumbens core. Behavioral Neuroscience, 116(4), 539-552.

Liao, R. M., \& Chuang, F. J. (2003). Differential effects of diazepam infused into the amygdala and hippocampus on negative contrast. Pharmacology, Biochemistry and Behavior, 74(4), 953-960.

Linnoila, M., Virkkunen, M., George, T., \& Higley, D. (1993). Impulse control disorders. International Clinical Psychopharmacology, 8(Suppl. 1), 53-56.

Linnoila, M., Virkkunen, M., Scheinin, M., Nuutila, A., Rimon, R., \& Goodwin, F. K. (1983). Low cerebrospinal fluid 5-hydroxyindoleacetic acid concentration differentiates impulsive from nonimpulsive violent behavior. Life Sciences, 33(26), 2609-2614.

Liu, Y. P., Wilkinson, L. S., \& Robbins, T. W. (2004). Effects of acute and chronic buspirone on impulsive choice and efflux of 5-HT and dopamine in hippocampus, nucleus accumbens and prefrontal cortex. Psychopharmacology, 173(1-2), 175-185.

Loewenstein, G. (1996). Out of control: Visceral influences on behavior. Organizational Behavior and Human Decision Processes, 63, 272-292.

Loewenstein, G. F., \& O’Donoghue, T. (2004). Animal spirits: Affective and deliberative processes in economic behavior. http://ssrn.com/abstract=539843. 
Logue, A. W., Tobin, H., Chelonis, J. J., Wang, R. Y., Geary, N., \& Schachter, S. (1992). Cocaine decreases self-control in rats: A preliminary report. Psychopharmacology, 109(1-2), 245-247.

Mackintosh, N. J. (1974). The psychology of animal learning. London: Academic Press.

Mackintosh, N. J. (1983). Conditioning and associative learning. Oxford: Oxford University Press.

Madden, G. J., Bickel, W. K., \& Jacobs, E. A. (1999). Discounting of delayed rewards in opioid-dependent outpatients: Exponential or hyperbolic discounting functions? Experimental and Clinical Psychopharmacology, 7(3), 284-293.

Madden, G. J., Petry, N. M., Badger, G. J., \& Bickel, W. K. (1997). Impulsive and self-control choices in opioid-dependent patients and nondrug-using control participants: Drug and monetary rewards. Experimental and Clinical Psychopharmacology, 5(3), 256-262.

Maldonado-Irizarry, C. S., \& Kelley, A. E. (1995). Excitotoxic lesions of the core and shell subregions of the nucleus accumbens differentially disrupt body-weight regulation and motor activity in the rat. Brain Research Bulletin, 38(6), 551-559.

Manes, F., Sahakian, B., Clark, L., Rogers, R., Antoun, N., Aitken, M., et al. (2002). Decision-making processes following damage to the prefrontal cortex. Brain, 125(Pt 3), 624-639.

Mann, J. J. (2003). Neurobiology of suicidal behaviour. Nature Reviews Neuroscience, 4(10), 819-828.

Maren, S., \& Fanselow, M. S. (1997). Electrolytic lesions of the fimbria/fornix, dorsal hippocampus, or entorhinal cortex produce anterograde deficits in contextual fear conditioning in rats. Neurobiology of Learning and Memory, 67(2), 142-149.

Martin, P. D., \& Ono, T. (2000). Effects of reward anticipation, reward presentation, and spatial parameters on the firing of single neurons recorded in the subiculum and nucleus accumbens of freely moving rats. Behavioural Brain Research, 116(1), 23-38.

Martin-Iverson, M. T., Wilkie, D., \& Fibiger, H. C. (1987). Effects of haloperidol and d-amphetamine on perceived quantity of food and tones. Psychopharmacology, 93(3), 374-381.

Matthews, S. C., Simmons, A. N., Lane, S. D., \& Paulus, M. P. (2004). Selective activation of the nucleus accumbens during risk-taking decision making. Neuroreport, 15(13), 2123-2127.

Maurice, N., Deniau, J. M., Glowinski, J., \& Thierry, A. M. (1998). Relationships between the prefrontal cortex and the basal ganglia in the rat: Physiology of the corticosubthalamic circuits. Journal of Neuroscience, 18(22), 9539-9546.

Mazur, J. E. (1987). An adjusting procedure for studying delayed reinforcement. In M. L. Commons, J. E. Mazur, J. A. Nevin, \& H. Rachlin (Eds.), Quantitative analyses of behavior: V. The effect of delay and of intervening events on reinforcement value (pp. 55-73). Hillsdale, New Jersey: Lawrence Erlbaum.

Mazur, J. E. (1989). Theories of probabilistic reinforcement. Journal of the Experimental Analysis of Behavior, 51(1), 87-99.

Mazur, J. E. (1995). Conditioned reinforcement and choice with delayed and uncertain primary reinforcers. Journal of the Experimental Analysis of Behavior, 63(2), 139-150.

Mazur, J. E. (1997). Choice, delay, probability, and conditioned reinforcement. Animal Learning \& Behavior, 25(2), 131-147.

Mazur, J. E., Stellar, J. R., \& Waraczynski, M. (1987). Self-control choice with electrical stimulation of the brain as a reinforcer. Behavioural Processes, 15(2-3), 143-153.

McClure, S. M., Daw, N. D., \& Montague, P. R. (2003). A computational substrate for incentive salience. Trends in Neurosciences, 26(8), 423-428.

McClure, S. M., Laibson, D. I., Loewenstein, G., \& Cohen, J. D. (2004). Separate neural systems value immediate and delayed monetary rewards. Science, 306(5695), 503-507.

Meck, W. H. (1988). Hippocampal function is required for feedback control of an internal clock's criterion. Behavioral Neuroscience, 102(1), 54-60.

Meck, W. H., Church, R. M., \& Olton, D. S. (1984). Hippocampus, time, and memory. Behavioral Neuroscience, 98(1), 3-22.
Mehlman, P. T., Higley, J. D., Faucher, I., Lilly, A. A., Taub, D. M., Vickers, J., et al. (1994). Low CSF 5-HIAA concentrations and severe aggression and impaired impulse control in nonhuman primates. American Journal of Psychiatry, 151, 1485-1491.

Mingote, S., Weber, S. M., Ishiwari, K., Correa, M., \& Salamone, J. D. (2005). Ratio and time requirements on operant schedules: Effort-related effects of nucleus accumbens dopamine depletions. European Journal of Neuroscience, 21(6), 1749-1757.

Mischel, W. (1966). Theory and research on the antecedents of self-imposed delay of reward. In B. A. Maher (Ed.), Progress in experimental personality research: Vol. 3 (pp. 85-132). New York: Academic Press.

Mishkin, M., Malamut, B., \& Bachevalier, J. (1984). Memories and habits: Two neural systems. In G. Lynch, J. L. McGaugh, \& N. M. Weinberger (Eds.), Neurobiology of learning and memory (pp. 65-77). New York: Guildford Press.

Mitchell, S. H. (1999). Measures of impulsivity in cigarette smokers and nonsmokers. Psychopharmacology, 146(4), 455-464.

Mitchell, S. H. (2003). Discounting the value of commodities according to different types of cost. In N. Heather, \& R. E. Vuchinich (Eds.), Choice, behavioral economics and addiction (pp. 339-357). Oxford: Elsevier.

Mitchell, S. H. (2004a). Effects of short-term nicotine deprivation on decisionmaking: Delay, uncertainty and effort discounting. Nicotine \& Tobacco Research, 6(5), 819-828.

Mitchell, S. H. (2004b). Measuring impulsivity and modeling its association with cigarette smoking. Behavioral and Cognitive Neuroscience Reviews, 3(4), 261-275.

Miyazaki, K., Mogi, E., Araki, N., \& Matsumoto, G. (1998). Reward-quality dependent anticipation in rat nucleus accumbens. Neuroreport, 9(17), 3943-3948.

Mobini, S., Body, S., Ho, M. Y., Bradshaw, C. M., Szabadi, E., Deakin, J. F., et al. (2002). Effects of lesions of the orbitofrontal cortex on sensitivity to delayed and probabilistic reinforcement. Psychopharmacology, 160(3), 290-298.

Mobini, S., Chiang, T. J., Al-Ruwaitea, A. S., Ho, M. Y., Bradshaw, C. M., \& Szabadi, E. (2000). Effect of central 5-hydroxytryptamine depletion on inter-temporal choice: A quantitative analysis. Psychopharmacology, 149(3), 313-318.

Mobini, S., Chiang, T. J., Ho, M. Y., Bradshaw, C. M., \& Szabadi, E. (2000). Effects of central 5-hydroxytryptamine depletion on sensitivity to delayed and probabilistic reinforcement. Psychopharmacology, 152(4), 390-397.

Mowrer, O. H. (1960). Learning theory and behavior. New York: Wiley.

Muir, J. L., Everitt, B. J., \& Robbins, T. W. (1996). The cerebral cortex of the rat and visual attentional function: Dissociable effects of mediofrontal, cingulate, anterior dorsolateral, and parietal cortex lesions on a five-choice serial reaction time task. Cerebral Cortex, 6(3), 470-481.

Myerson, J., \& Green, L. (1995). Discounting of delayed rewards: Models of individual choice. Journal of the Experimental Analysis of Behavior, 64, 263-276.

Myerson, J., Green, L., Hanson, J. S., Hold, D. D., \& Estle, S. J. (2003). Discounting delayed and probabilistic rewards: Processes and traits. Journal of Economic Psychology, 24(5), 619-635.

Niv, Y., Duff, M. O., \& Dayan, P. (2005). Dopamine, uncertainty and TD learning. Behavioral and Brain Functions, 1, 6.

O'Carroll, R. E., \& Papps, B. P. (2003). Decision making in humans: The effect of manipulating the central noradrenergic system. Journal of Neurology, Neurosurgery and Psychiatry, 74(3), 376-378.

O’Doherty, J., Dayan, P., Schultz, J., Deichmann, R., Friston, K., \& Dolan, R. J. (2004). Dissociable roles of ventral and dorsal striatum in instrumental conditioning. Science, 304(5669), 452-454.

Ohmura, Y., Takahashi, T., \& Kitamura, N. (2005). Discounting delayed and probabilistic monetary gains and losses by smokers of cigarettes. Psychopharmacology, 182(4), 508-515.

Olton, D. S., Meck, W. H., \& Church, R. M. (1987). Separation of hippocampal and amygdaloid involvement in temporal memory dysfunctions. Brain Research, 404(1-2), 180-188.

Ortner, C. N., MacDonald, T. K., \& Olmstead, M. C. (2003). Alcohol intoxication reduces impulsivity in the delay-discounting paradigm. Alcohol and Alcoholism, 38(2), 151-156. 
Ostaszewski, P., Green, L., \& Myerson, J. (1998). Effects of inflation on the subjective value of delayed and probabilistic rewards. Psychonomic Bulletin \& Review, 5, 324-333.

Ostaszewski, P., \& Karzel, K. (2002). Discounting of delayed and probabilistic losses of different amounts. European Psychologist, 7, 295-301.

OUP, (1997). New shorter Oxford English dictionary. Oxford, UK: Oxford University Press.

Packard, M. G., \& McGaugh, J. L. (1996). Inactivation of hippocampus or caudate nucleus with lidocaine differentially affects expression of place and response learning. Neurobiology of Learning and Memory, 65(1), 65-72.

Paine, T. A., Dringenberg, H. C., \& Olmstead, M. C. (2003). Effects of chronic cocaine on impulsivity: Relation to cortical serotonin mechanisms. Behavioural Brain Research, 147(1-2), 135-147.

Papa, M., Sagvolden, T., Sergeant, J. A., \& Sadile, A. G. (1996). Reduced CaMKII-positive neurones in the accumbens shell of an animal model of attention-deficit hyperactivity disorder. Neuroreport, 7(18), 3017-3020.

Papa, M., Sergeant, J. A., \& Sadile, A. G. (1998). Reduced transduction mechanisms in the anterior accumbal interface of an animal model of attention-deficit hyperactivity disorder. Behavioural Brain Research, 94(1), 187-195.

Parkinson, J. A., Cardinal, R. N., \& Everitt, B. J. (2000). Limbic cortical-ventral striatal systems underlying appetitive conditioning. Progress in Brain Research, 126, 263-285.

Parkinson, J. A., Dalley, J. W., Cardinal, R. N., Bamford, A., Fehnert, B., Lachenal, G., et al. (2002). Nucleus accumbens dopamine depletion impairs both acquisition and performance of appetitive Pavlovian approach behaviour: Implications for mesoaccumbens dopamine function. Behavioural Brain Research, 137, 149-163.

Parkinson, J. A., Olmstead, M. C., Burns, L. H., Robbins, T. W., \& Everitt, B. J. (1999). Dissociation in effects of lesions of the nucleus accumbens core and shell on appetitive Pavlovian approach behavior and the potentiation of conditioned reinforcement and locomotor activity by d-amphetamine. Journal of Neuroscience, 19(6), 2401-2411.

Parkinson, J. A., Robbins, T. W., \& Everitt, B. J. (1999). Selective excitotoxic lesions of the nucleus accumbens core and shell differentially affect aversive Pavlovian conditioning to discrete and contextual cues. Psychobiology, 27(2), 256-266.

Parkinson, J. A., Willoughby, P. J., Robbins, T. W., \& Everitt, B. J. (2000). Disconnection of the anterior cingulate cortex and nucleus accumbens core impairs Pavlovian approach behavior: Further evidence for limbic cortical-ventral striatopallidal systems. Behavioral Neuroscience, 114(1), $42-63$.

Paulus, M. P., Rogalsky, C., Simmons, A., Feinstein, J. S., \& Stein, M. B. (2003). Increased activation in the right insula during risk-taking decision making is related to harm avoidance and neuroticism. Neuroimage, 19(4), 1439-1448.

Perin, C. T. (1943). A quantitative investigation of the delay-of-reinforcement gradient. Journal of Experimental Psychology, 32, 37-51.

Petry, N. M. (2001). Delay discounting of money and alcohol in actively using alcoholics, currently abstinent alcoholics, and controls. Psychopharmacology, 154(3), 243-250.

Phillips, R. G., \& LeDoux, J. E. (1992). Differential contribution of amygdala and hippocampus to cued and contextual fear conditioning. Behavioral Neuroscience, 106(2), 274-285.

Phillips, R. G., \& LeDoux, J. E. (1994). Lesions of the dorsal hippocampal formation interfere with background but not foreground contextual fear conditioning. Learning \& Memory, 1(1), 34-44.

Phillips, R. G., \& LeDoux, J. E. (1995). Lesions of the fornix but not the entorhinal or perirhinal cortex interfere with contextual fear conditioning. Journal of Neuroscience, $15(7 \mathrm{Pt} 2), 5308-5315$.

Plutchik, R., \& Van Praag, H. (1989). The measurement of suicidality, aggressivity and impulsivity. Progress in Neuro-Psychopharmacology and Biological Psychiatry, 13(Suppl), S23-S34.

Port, R. L., Romano, A. G., Steinmetz, J. E., Mikhail, A. A., \& Patterson, M. M. (1986). Retention and acquisition of classical trace conditioned responses by rabbits with hippocampal lesions. Behavioral Neuroscience, 100(5), 745-752.
Pothuizen, H. H., Jongen-Relo, A. L., Feldon, J., \& Yee, B. K. (2005). Double dissociation of the effects of selective nucleus accumbens core and shell lesions on impulsive-choice behaviour and salience learning in rats. European Journal of Neuroscience, 22(10), 2605-2616.

Pothuizen, H. H., Jongen-Relo, A. L., Feldon, J., \& Yee, B. K. (2006). Latent inhibition of conditioned taste aversion is not disrupted, but can be enhanced, by selective nucleus accumbens shell lesions in rats. Neuroscience, 137(4), 1119-1130.

Poulos, C. X., Le, A. D., \& Parker, J. L. (1995). Impulsivity predicts individual susceptibility to high levels of alcohol self-administration. Behavioural Pharmacology, 6(8), 810-814.

Poulos, C. X., Parker, J. L., \& Le, A. D. (1996). Dexfenfluramine and 8-OH-DPAT modulate impulsivity in a delay-of-reward paradigm: Implications for a correspondence with alcohol consumption. Behavioural Pharmacology, 7(4), 395-399.

Rachlin, H., Brown, J., \& Cross, D. (2000). Discounting in judgments of delay and probability. Journal of Behavioral Decision Making, 13, 145-149.

Rachlin, H., Castrogiovanni, A., \& Cross, D. (1987). Probability and delay in commitment. Journal of the Experimental Analysis of Behavior, 48(3), 347-353.

Rachlin, H., Logue, A. W., Gibbon, J., \& Frankel, M. (1986). Cognition and behavior in studies of choice. Psychological Review, 93, 33-45.

Rachlin, H., Raineri, A., \& Cross, D. (1991). Subjective probability and delay. Journal of the Experimental Analysis of Behavior, 55(2), 233-244.

Rachlin, H., \& Siegel, E. (1994). Temporal patterning in probabilistic choice. Organizational Behavior and Human Decision Processes, 59, 161-176.

Rahman, S., Sahakian, B. J., Cardinal, R. N., Rogers, R. D., \& Robbins, T. W. (2001). Decision making and neuropsychiatry. Trends in Cognitive Sciences, 5, 271-277.

Rawlins, J. N., Feldon, J., \& Butt, S. (1985). The effects of delaying reward on choice preference in rats with hippocampal or selective septal lesions. Behavioural Brain Research, 15(3), 191-203.

Rawlins, J. N., Winocur, G., \& Gray, J. A. (1983). The hippocampus, collateral behavior, and timing. Behavioral Neuroscience, 97(6), 857-872.

Reading, P. J., \& Dunnett, S. B. (1991). The effects of excitotoxic lesions of the nucleus accumbens on a matching to position task. Behavioural Brain Research, 46(1), 17-29.

Reading, P. J., \& Dunnett, S. B. (1995). Embryonic striatal grafts reverse the disinhibitory effects of ibotenic acid lesions of the ventral striatum. Experimental Brain Research, 105(1), 76-86.

Revusky, S., \& Garcia, J. (1970). Learned associations over long delays. In G. H. Bower (Ed.), The psychology of learning and motivation: Vol. 4 (pp. 1-84). New York: Academic Press.

Reynolds, B., Richards, J. B., Horn, K., \& Karraker, K. (2004). Delay discounting and probability discounting as related to cigarette smoking status in adults. Behavioural Processes, 65(1), 35-42.

Richards, J. B., Chock, M. A., Carlson, B., de Wit, H., \& Seiden, L. (1997). Comparison of two models of impulsive behavior in rats: Effects of amphetamine and haloperidol. Society for Neuroscience Abstracts, 23(2), 2406.

Richards, J. B., Mitchell, S. H., de Wit, H., \& Seiden, L. S. (1997). Determination of discount functions in rats with an adjusting-amount procedure. Journal of the Experimental Analysis of Behavior, 67(3), 353-366.

Richards, J. B., Sabol, K. E., \& de Wit, H. (1999). Effects of methamphetamine on the adjusting amount procedure, a model of impulsive behavior in rats. Psychopharmacology, 146(4), 432-439.

Richards, J. B., \& Seiden, L. S. (1995). Serotonin depletion increases impulsive behavior in rats. Society for Neuroscience Abstracts, 21, 1693.

Richards, J. B., Zhang, L., Mitchell, S. H., \& de Wit, H. (1999). Delay or probability discounting in a model of impulsive behavior: Effect of alcohol. Journal of the Experimental Analysis of Behavior, 71(2), 121-143.

Richardson, N. R., \& Gratton, A. (1998). Changes in medial prefrontal cortical dopamine levels associated with response-contingent food reward: An electrochemical study in rat. Journal of Neuroscience, 18(21), 9130-9138.

Robbins, T. W. (1976). Relationship between reward-enhancing and stereotypical effects of psychomotor stimulant drugs. Nature, 264(5581), $57-59$. 
Robbins, T. W. (1978). The acquisition of responding with conditioned reinforcement: Effects of pipradrol, methylphenidate, d-amphetamine, and nomifensine. Psychopharmacology, 58(1), 79-87.

Robbins, T. W., Cardinal, R. N., Di Ciano, P., Halligan, P. W., Hellemans, K. G. C., Lee, J. L. C., et al. (2005). Neuroscience of drugs and addiction [Foresight: Brain Science, Addiction and Drugs project; www.foresight.gov.uk]. London, UK: UK Office of Science and Technology.

Robbins, T. W., \& Everitt, B. J. (1992). Functions of dopamine in the dorsal and ventral striatum. Seminars in the Neurosciences, 4, 119-127.

Robbins, T. W., \& Everitt, B. J. (1996). Neurobehavioural mechanisms of reward and motivation. Current Opinion in Neurobiology, 6(2), 228-236.

Robbins, T. W., Watson, B. A., Gaskin, M., \& Ennis, C. (1983). Contrasting interactions of pipradrol, d-amphetamine, cocaine, cocaine analogues, apomorphine and other drugs with conditioned reinforcement. Psychopharmacology, 80(2), 113-119.

Roberts, S. (1981). Isolation of an internal clock. Journal of Experimental Psychology: Animal Behavior Processes, 7, 242-268.

Rogers, R. D., Everitt, B. J., Baldacchino, A., Blackshaw, A. J., Swainson, R., Wynne, K., et al. (1999). Dissociable deficits in the decisionmaking cognition of chronic amphetamine abusers, opiate abusers, patients with focal damage to prefrontal cortex, and tryptophandepleted normal volunteers: Evidence for monoaminergic mechanisms. Neuropsychopharmacology, 20(4), 322-339.

Rogers, R. D., Lancaster, M., Wakeley, J., \& Bhagwagar, Z. (2004). Effects of beta-adrenoceptor blockade on components of human decision-making. Psychopharmacology, 172(2), 157-164.

Rogers, R. D., Owen, A. M., Middleton, H. C., Williams, E. J., Pickard, J. D., Sahakian, B. J., et al. (1999). Choosing between small, likely rewards and large, unlikely rewards activates inferior and orbital prefrontal cortex. Journal of Neuroscience, 19(20), 9029-9038.

Rogers, R. D., Ramnani, N., Mackay, C., Wilson, J. L., Jezzard, P., Carter, C. S., et al. (2004). Distinct portions of anterior cingulate cortex and medial prefrontal cortex are activated by reward processing in separable phases of decision-making cognition. Biological Psychiatry, 55(6), 594-602.

Rogers, R. D., Tunbridge, E. M., Bhagwagar, Z., Drevets, W. C., Sahakian, B. J., \& Carter, C. S. (2003). Tryptophan depletion alters the decisionmaking of healthy volunteers through altered processing of reward cues. Neuropsychopharmacology, 28(1), 153-162.

Rotter, J. B. (1954). Social learning and clinical psychology. Englewood Cliffs, NJ: Prentice-Hall.

Roy, A., DeJong, J., \& Linnoila, M. (1989). Extraversion in pathological gamblers: Correlates with indices of noradrenergic function. Archives of General Psychiatry, 46, 679-681.

Rubia, K., Overmeyer, S., Taylor, E., Brammer, M., Williams, S. C. R., Simmons, A., et al. (1999). Hypofrontality in attention deficit hyperactivity disorder during higher-order motor control: A study with functional MRI. American Journal of Psychiatry, 156(6), 891-896.

Rudy, J. W., Barrientos, R. M., \& O'Reilly, R. C. (2002). Hippocampal formation supports conditioning to memory of a context. Behavioral Neuroscience, 116(4), 530-538.

Russell, S. J., \& Norvig, P. N. (1995). Artificial intelligence: A modern approach. Upper Saddle River, New Jersey: Prentice-Hall.

Russell, V., de Villiers, A., Sagvolden, T., Lamm, M., \& Taljaard, J. (1998). Differences between electrically-, ritalin- and D-amphetamine- stimulated release of [H-3]dopamine from brain slices suggest impaired vesicular storage of dopamine in an animal model of attention-deficit hyperactivity disorder. Behavioural Brain Research, 94(1), 163-171.

Russell, V., Devilliers, A., Sagvolden, T., Lamm, M., \& Taljaard, J. (1995). Altered dopaminergic function in the prefrontal cortex, nucleus accumbens and caudate-putamen of an animal model of attention-deficit hyperactivity disorder-the spontaneously hypertensive rat. Brain Research, 676(2), 343-351.

Russell, V. A. (2000). The nucleus accumbens motor-limbic interface of the spontaneously hypertensive rat as studied in vitro by the superfusion slice technique. Neuroscience and Biobehavioral Reviews, 24(1), 133-136.

Russell, V. A., Sagvolden, T., \& Johansen, E. B. (2005). Animal models of attention-deficit hyperactivity disorder. Behavioral and Brain Functions, 1, 9.
Sadile, A. G. (2000). Multiple evidence of a segmental defect in the anterior forebrain of an animal model of hyperactivity and attention deficit. Neuroscience and Biobehavioral Reviews, 24(1), 161-169.

Sagvolden, T. (2000). Behavioral validation of the spontaneously hypertensive rat (SHR) as an animal model of attention-deficit/hyperactivity disorder (AD/HD). Neuroscience and Biobehavioral Reviews, 24(1), 31-39.

Sagvolden, T., Aase, H., Zeiner, P., \& Berger, D. (1998). Altered reinforcement mechanisms in attention-deficit/hyperactivity disorder. Behavioural Brain Research, 94(1), 61-71.

Sagvolden, T., Metzger, M. A., Schiorbeck, H. K., Rugland, A. L., Spinnangr, I., \& Sagvolden, G. (1992). The spontaneously hypertensive rat (SHR) as an animal model of childhood hyperactivity (ADHD): Changed reactivity to reinforcers and to psychomotor stimulants. Behavioral and Neural Biology, 58(2), 103-112.

Sagvolden, T., Pettersen, M. B., \& Larsen, M. C. (1993). Spontaneously hypertensive rats (SHR) as a putative animal model of childhood hyperkinesis: SHR behavior compared to four other rat strains. Physiology and Behavior, 54(6), 1047-1055.

Sagvolden, T., \& Sergeant, J. A. (1998). Attention deficit/hyperactivity disorder-from brain dysfunctions to behaviour. Behavioural Brain Research, 94(1), 1-10.

Salamone, J. D. (1994). The involvement of nucleus accumbens dopamine in appetitive and aversive motivation. Behavioural Brain Research, 61(2), $117-133$.

Salamone, J. D., \& Correa, M. (2002). Motivational views of reinforcement: Implications for understanding the behavioral functions of nucleus accumbens dopamine. Behavioural Brain Research, 137(1-2), 3-25.

Salamone, J. D., Correa, M., Mingote, S. M., \& Weber, S. M. (2003). Nucleus accumbens dopamine and the regulation of effort in food-seeking behavior: Implications for studies of natural motivation, psychiatry, and drug abuse. Journal of Pharmacology and Experimental Therapeutics, 305(1), 1-8.

Salamone, J. D., Correa, M., Mingote, S. M., \& Weber, S. M. (2005). Beyond the reward hypothesis: Alternative functions of nucleus accumbens dopamine. Current Opinion in Pharmacology, 5(1), 34-41.

Salamone, J. D., Cousins, M. S., \& Bucher, S. (1994). Anhedonia or anergia? Effects of haloperidol and nucleus accumbens dopamine depletion on instrumental response selection in a T-maze cost/benefit procedure. Behavioural Brain Research, 65(2), 221-229.

Salamone, J. D., Cousins, M. S., \& Snyder, B. J. (1997). Behavioral functions of nucleus accumbens dopamine: Empirical and conceptual problems with the anhedonia hypothesis. Neuroscience and Biobehavioral Reviews, 21(3), 341-359.

Salamone, J. D., Wisniecki, A., Carlson, B. B., \& Correa, M. (2001). Nucleus accumbens dopamine depletions make animals highly sensitive to high fixed ratio requirements but do not impair primary food reinforcement. Neuroscience, 105(4), 863-870.

Salinas, J. A., Introini-Collison, I. B., Dalmaz, C., \& McGaugh, J. L. (1997). Posttraining intraamygdala infusions of oxotremorine and propranolol modulate storage of memory for reductions in reward magnitude. Neurobiology of Learning and Memory, 68(1), 51-59.

Salinas, J. A., \& McGaugh, J. L. (1996). The amygdala modulates memory for changes in reward magnitude: Involvement of the amygdaloid GABAergic system. Behavioural Brain Research, 80(1-2), 87-98.

Salinas, J. A., Packard, M. G., \& McGaugh, J. L. (1993). Amygdala modulates memory for changes in reward magnitude: Reversible posttraining inactivation with lidocaine attenuates the response to a reduction in reward. Behavioural Brain Research, 59(1-2), 153-159.

Schultz, W. (1998). Predictive reward signal of dopamine neurons. Journal of Neurophysiology, 80(1), 1-27.

Schultz, W., Apicella, P., Romo, R., \& Scarnati, E. (1995). Context-dependent activity in primate striatum reflecting past and future behavioral events. In J. C. Houk, J. L. Davis, \& D. G. Beiser (Eds.), Models of information processing in the basal ganglia (pp. 11-27). Cambridge, Massachusetts, London: MIT Press.

Schultz, W., Apicella, P., Scarnati, E., \& Ljungberg, T. (1992). Neuronal activity in monkey ventral striatum related to the expectation of reward. Journal of Neuroscience, 12(12), 4595-4610. 
Schultz, W., Dayan, P., \& Montague, P. R. (1997). A neural substrate of prediction and reward. Science, 275(5306), 1593-1599.

Schultz, W., \& Dickinson, A. (2000). Neuronal coding of prediction errors. Annual Review of Neuroscience, 23, 473-500.

Schultz, W., Tremblay, L., \& Hollerman, J. R. (1998). Reward prediction in primate basal ganglia and frontal cortex. Neuropharmacology, 37(4-5), 421-429.

Schultz, W., Tremblay, L., \& Hollerman, J. R. (2000). Reward processing in primate orbitofrontal cortex and basal ganglia. Cerebral Cortex, 10(3), 272-284.

Seeman, P., \& Madras, B. (2002). Methylphenidate elevates resting dopamine which lowers the impulse-triggered release of dopamine: A hypothesis. Behavioural Brain Research, 130(1-2), 79-83.

Selden, N. R., Everitt, B. J., Jarrard, L. E., \& Robbins, T. W. (1991). Complementary roles for the amygdala and hippocampus in aversive conditioning to explicit and contextual cues. Neuroscience, 42(2), 335-350.

Shastri, L., \& Ajjanagadde, V. (1993). From simple associations to systematic reasoning: A connectionist representation of rules, variables and dynamic bindings using temporal synchrony. Behavioral and Brain Sciences, 16, 417-494.

Skinner, B. F. (1938). The behavior of organisms: An experimental analysis. New York: Appleton.

Solanto, M. V. (1998). Neuropsychopharmacological mechanisms of stimulant drug action in attention-deficit hyperactivity disorder: A review and integration. Behavioural Brain Research, 94(1), 127-152.

Solanto, M. V. (2002). Dopamine dysfunction in AD/HD: Integrating clinical and basic neuroscience research. Behavioural Brain Research, 130(1-2), $65-71$.

Sonuga-Barke, E. J. (2002). Psychological heterogeneity in AD/HD—a dual pathway model of behaviour and cognition. Behavioural Brain Research, 130(1-2), 29-36.

Soubrié, P. (1986). Reconciling the role of central serotonin neurons in human and animal behavior. Behavioral and Brain Sciences, 9(2), 319-335.

Sougné, J. (1998). Connectionism and the problem of multiple instantiation. Trends in Cognitive Sciences, 2, 183-189.

Sozou, P. D. (1998). On hyperbolic discounting and uncertain hazard rates. Proceedings of the Royal Society of London. Series B: Biological Sciences, 265, 2015-2020. doi:10.1098/rspb.1998.0534.

Spence, K. W. (1956). Behavior Theory and Conditioning. Englewood Cliffs, New Jersey: Prentice-Hall.

Stevenson, M. K. (1986). A discounting model for decisions with delayed positive and negative outcomes. Journal of Experimental Psychology: General, 115(2), 131-154.

Stockmeier, C. A. (2003). Involvement of serotonin in depression: Evidence from postmortem and imaging studies of serotonin receptors and the serotonin transporter. Journal of Psychiatric Research, 37(5), 357-373.

Stratford, T. R., \& Kelley, A. E. (1997). GABA in the nucleus accumbens shell participates in the central regulation of feeding behavior. Journal of Neuroscience, 17(11), 4434-4440.

Sutton, R. S. (1988). Learning to predict by the method of temporal differences. Machine Learning, 3, 9-44.

Swanson, C. J., Heath, S., Stratford, T. R., \& Kelley, A. E. (1997). Differential behavioral responses to dopaminergic stimulation of nucleus accumbens subregions in the rat. Pharmacology Biochemistry and Behavior, 58(4), 933-945.

Swanson, J., Castellanos, F. X., Murias, M., LaHoste, G., \& Kennedy, J. (1998). Cognitive neuroscience of attention deficit hyperactivity disorder and hyperkinetic disorder. Current Opinion in Neurobiology, 8(2), 263-271.

Taylor, J. R., \& Robbins, T. W. (1984). Enhanced behavioural control by conditioned reinforcers following microinjections of d-amphetamine into the nucleus accumbens. Psychopharmacology, 84(3), 405-412.

Taylor, J. R., \& Robbins, T. W. (1986). 6-Hydroxydopamine lesions of the nucleus accumbens, but not of the caudate nucleus, attenuate enhanced responding with reward-related stimuli produced by intra-accumbens d-amphetamine. Psychopharmacology, 90(3), 390-397.

Thorndike, E. L. (1911). Animal intelligence: Experimental studies. New York: Macmillan.
Tobler, P. N., Fiorillo, C. D., \& Schultz, W. (2005). Adaptive coding of reward value by dopamine neurons. Science, 307(5715), 1642-1645.

Tolman, E. C. (1932). Purposive behavior in animals and men. New York: Century.

Tomie, A., Aguado, A. S., Pohorecky, L. A., \& Benjamin, D. (1998). Ethanol induces impulsive-like responding in a delay-of-reward operant choice procedure: Impulsivity predicts autoshaping. Psychopharmacology, 139, 376-382.

Träskman-Bendz, L., Åsberg, M., \& Schalling, D. (1986). Serotonergic function and suicidal behavior in personality disorders. Annals of the New York Academy of Sciences, 487, 168-174.

Tzschentke, T. M. (2000). The medial prefrontal cortex as a part of the brain reward system. Amino Acids, 19(1), 211-219.

Ungerstedt, U. (1971). Stereotaxic mapping of the monoamine pathways in the rat brain. Acta Physiologica Scandinavica, 82(Suppl. 367), 1-48.

Uylings, H. B., Groenewegen, H. J., \& Kolb, B. (2003). Do rats have a prefrontal cortex? Behavioural Brain Research, 146(1-2), 3-17.

Vuchinich, R. E., \& Calamas, M. L. (1997). Does the repeated gambles procedure measure impulsivity in social drinkers? Experimental and Clinical Psychopharmacology, 5(2), 157-162.

Wade, T. R., de Wit, H., \& Richards, J. B. (2000). Effects of dopaminergic drugs on delayed reward as a measure of impulsive behavior in rats. Psychopharmacology, 150, 90-101.

Wakabayashi, K. T., Fields, H. L., \& Nicola, S. M. (2004). Dissociation of the role of nucleus accumbens dopamine in responding to reward-predictive cues and waiting for reward. Behavioural Brain Research, 154(1), 19-30.

Walderhaug, E., Lunde, H., Nordvik, J. E., Landro, N. I., Refsum, H., \& Magnusson, A. (2002). Lowering of serotonin by rapid tryptophan depletion increases impulsiveness in normal individuals. Psychopharmacology, 164(4), 385-391.

Wallenstein, G. V., Eichenbaum, H., \& Hasselmo, M. E. (1998). The hippocampus as an associator of discontiguous events. Trends in Neurosciences, 21(8), 317-323.

Walton, M. E., Bannerman, D. M., Alterescu, K., \& Rushworth, M. F. (2003). Functional specialization within medial frontal cortex of the anterior cingulate for evaluating effort-related decisions. Journal of Neuroscience, 23(16), 6475-6479.

Walton, M. E., Bannerman, D. M., \& Rushworth, M. F. (2002). The role of rat medial frontal cortex in effort-based decision making. Journal of Neuroscience, 22(24), 10996-11003.

Walton, M. E., Croxson, P. L., Rushworth, M. F., \& Bannerman, D. M. (2005). The mesocortical dopamine projection to anterior cingulate cortex plays no role in guiding effort-related decisions. Behavioral Neuroscience, 119(1), 323-328.

Watkins, C. J. C. H. 1989. Learning from delayed rewards. Unpublished Ph.D. thesis. Cambridge. University of Cambridge.

White, K. G., \& Pipe, M. E. (1987). Sensitivity to reinforcer duration in a selfcontrol procedure. Journal of the Experimental Analysis of Behavior, 48, 235-250.

White, N. M. (1997). Mnemonic functions of the basal ganglia. Current Opinion in Neurobiology, 7, 164-169.

Williams, B. A., \& Dunn, R. (1991). Preference for conditioned reinforcement. Journal of the Experimental Analysis of Behavior, 55(1), 37-46.

Williams, J., \& Dayan, P. (2005). Dopamine, learning, and impulsivity: A biological account of attention-deficit/hyperactivity disorder. Journal of Child and Adolescent Psychopharmacology, 15(2), 160-179; discussion 157-169.

Williams, W. A., Shoaf, S. E., Hommer, D., Rawlings, R., \& Linnoila, M. (1999). Effects of acute tryptophan depletion on plasma and cerebrospinal fluid tryptophan and 5-hydroxyindoleacetic acid in normal volunteers. Journal of Neurochemistry, 72(4), 1641-1647.

Winstanley, C. A., Baunez, C., Theobald, D. E., \& Robbins, T. W. (2005). Lesions to the subthalamic nucleus decrease impulsive choice but impair autoshaping in rats: The importance of the basal ganglia in Pavlovian conditioning and impulse control. European Journal of Neuroscience, 21(11), 3107-3116. 
Winstanley, C. A., Dalley, J. W., Theobald, D. E., \& Robbins, T. W. (2003). Global 5-HT depletion attenuates the ability of amphetamine to decrease impulsive choice on a delay-discounting task in rats. Psychopharmacology, 170(3), 320-331.

Winstanley, C. A., Dalley, J. W., Theobald, D. E., \& Robbins, T. W. (2004). Fractionating impulsivity: Contrasting effects of central 5-HT depletion on different measures of impulsive behavior. Neuropsychopharmacology, 29(7), 1331-1343.

Winstanley, C. A., Theobald, D. E., Cardinal, R. N., \& Robbins, T. W. (2004). Contrasting roles of basolateral amygdala and orbitofrontal cortex in impulsive choice. Journal of Neuroscience, 24(20), 4718-4722.

Winstanley, C. A., Theobald, D. E., Dalley, J. W., Glennon, J. C., \& Robbins, T. W. (2004). 5-HT2A and 5-HT2C receptor antagonists have opposing effects on a measure of impulsivity: Interactions with global 5-HT depletion. Psychopharmacology, 176(3-4), 376-385.

Winstanley, C. A., Theobald, D. E., Dalley, J. W., \& Robbins, T. W. (2005).
Interactions between serotonin and dopamine in the control of impulsive choice in rats: Therapeutic implications for impulse control disorders. Neuropsychopharmacology, 30(4), 669-682.

Wogar, M. A., Bradshaw, C. M., \& Szabadi, E. (1993). Effect of lesions of the ascending 5-hydroxytryptaminergic pathways on choice between delayed reinforcers. Psychopharmacology, 111(2), 239-243.

Wultz, B., Sagvolden, T., Moser, E. I., \& Moser, M. B. (1990). The spontaneously hypertensive rat as an animal model of attention-deficit hyperactivity disorder: Effects of methylphenidate on exploratory behavior. Behavioral and Neural Biology, 53(1), 88-102.

Yu, A. J., \& Dayan, P. (2005). Uncertainty, neuromodulation, and attention. Neuron, 46(4), 681-692.

Zhuang, X., Oosting, R. S., Jones, S. R., Gainetdinov, R. R., Miller, G. W., Caron, M. G., et al. (2001). Hyperactivity and impaired response habituation in hyperdopaminergic mice. Proceedings of the National Academy of Sciences of the United States of America, 98(4), 1982-1987. 